Article

\title{
Chitosan-Based Therapeutic Systems for Superficial Candidiasis Treatment. Synergetic Activity of Nystatin and Propolis
}

\author{
Andra-Cristina Humelnicu ${ }^{1}$, Petrișor Samoilă ${ }^{1}$ (D), Corneliu Cojocaru ${ }^{1}$ (D), Raluca Dumitriu ${ }^{1}$ (D), \\ Andra-Cristina Bostănaru ${ }^{2, *}$, Mihai Mareș ${ }^{2} \mathbb{D}$, Valeria Harabagiu ${ }^{1, *}$ and Bogdan C. Simionescu ${ }^{1}$
}

Citation: Humelnicu, A.-C.;

Samoilă, P.; Cojocaru, C.; Dumitriu, R.;

Bostănaru, A.-C.; Mareș, M.;

Harabagiu, V.; Simionescu, B.C.

Chitosan-Based Therapeutic Systems for Superficial Candidiasis Treatment. Synergetic Activity of Nystatin and

Propolis. Polymers 2022, 14, 689 .

https://doi.org/10.3390/

polym 14040689

Academic Editors: Iza Radecka and Barbara Trzebicka

Received: 10 January 2022

Accepted: 9 February 2022

Published: 11 February 2022

Publisher's Note: MDPI stays neutral with regard to jurisdictional claims in published maps and institutional affiliations.

Copyright: (C) 2022 by the authors. Licensee MDPI, Basel, Switzerland. This article is an open access article distributed under the terms and conditions of the Creative Commons Attribution (CC BY) license (https:// creativecommons.org/licenses/by/ $4.0 /)$
1 "Petru Poni" Institute of Macromolecular Chemistry, 41A Grigore Ghica Voda Alley, 700487 Iasi, Romania; humelnicu.andra@icmpp.ro (A.-C.H.); samoila.petrisor@icmpp.ro (P.S.); cojocaru.corneliu@icmpp.ro (C.C.); rdumi@icmpp.ro (R.D.); bcsimion@icmpp.ro (B.C.S.)

2 Laboratory of Antimicrobial Chemotherapy, Faculty of Veterinary Medicine, "Ion Ionescu de la Brad" Iasi University of Life Sciences (IULS), 8 Mihail Sadoveanu Alley, 700489 Iasi, Romania; mycomedica@gmail.com

* Correspondence: acbostanaru@gmail.com (A.-C.B.); hvaleria@icmpp.ro (V.H.)

\begin{abstract}
The paper deals with new approaches to chitosan (CS)-based antifungal therapeutic formulations designed to fulfill the requirements of specific applications. Gel-like formulations were prepared by mixing CS dissolved in aqueous lactic acid (LA) solution with nystatin (NYS) powder and/or propolis (PRO) aqueous solution dispersed in glycerin, followed by water evaporation to yield flexible mesoporous (pore widths of 2-4 nm) films of high specific surfaces between $1 \times 10^{3}$ and $1.7 \times 10^{3} \mathrm{~m}^{2} / \mathrm{g}$. Morphological evaluation of the antifungal films showed uniform dispersion and downsizing of NYS crystallites (with initial sizes up to $50 \mu \mathrm{m}$ ). Their mechanical properties were found to be close to those of soft tissues (Young's modulus values between 0.044-0.025 MPa). The films presented hydration capacities in physiological condition depending on their composition, i.e., higher for NYS-charged (628\%), as compared with PRO loaded films (118-129\%). All NYS charged films presented a quick release for the first $10 \mathrm{~min}$ followed by a progressive increase of the release efficiency at $48.6 \%$, for the samples containing NYS alone and decreasing values with increasing amount of PRO to $45.9 \%$ and $42.8 \%$ after $5 \mathrm{~h}$. By in vitro analysis, the hydrogels with acidic $\mathrm{pH}$ values around 3.8 were proven to be active against Candida albicans and Candida glabrata species. The time-killing assay performed during $24 \mathrm{~h}$ on Candida albicans in synthetic vagina-simulative medium showed that the hydrogel formulations containing both NYS and PRO presented the faster slowing down of the fungal growth, from colony-forming unit (CFU)/mL of $1.24 \times 10^{7}$ to $\mathrm{CFU} / \mathrm{mL}<10$ (starting from the first $6 \mathrm{~h}$ ).
\end{abstract}

Keywords: chitosan; drug delivery systems; nystatin; propolis; antifungal activity

\section{Introduction}

More than one billion people are affected by superficial Candida infections as oral candidiasis and vaginitis (vulvovaginal candidiasis) [1,2]. An improper treatment of these infections can lead to the fungi spreading from the surface of the body to the internal organs (kidneys, heart, brain) and to the blood, causing deadly invasive infections or candidemia [3]. Worldwide, the incidence of invasive Candida infections is increasing (700,000 cases annually), and is associated with considerable mortality [2,4]. The antagonistic augmentation of case numbers and geographical spread by the end of 2020 [5] requires an increased effort from scientists to promote appropriate prevention, protection and therapeutic systems, and to combat candidiasis in early stages.

The treatment of superficial candidiasis involves the development of mucoadhesive pharmaceutical systems for the local administration of antifungal agents. The polysaccharide- 
based therapeutic systems are known for achieving specific functions in a complex biological environment, since they are considered one of the most propitious subjects lying on the frontier between chemistry, biology, medicine, and bioengineering [6]. Undoubtedly, natural polymers are promptly recognized and embraced by the human body considering their biochemical similarity with extracellular matrix components [7]. Chitosan is a cationic amino-polysaccharide which possesses useful biological properties, such as mucoadhesion, antibacterial and antifungal activity, antioxidant, hemostatic, and antiseptic characteristics [8]. The reactive hydroxyl and amino groups on the chitosan chain facilitate different reactions with other active compounds and are able to perform a multitude of intermolecular and intramolecular interactions [9]. Moreover, chitosan-based therapeutic systems are known for their capacity to incorporate and release multiple active principles, either simultaneously or sequentially, for achieving more efficient associated therapy [10]. Therefore, this study is based on the well-known mucoadhesive properties of chitosan, but also on its resistance in contact with the oral and vaginal mucosa $[11,12]$.

Among the few classes of active principles with antifungal effect (azoles, polyenes, echinocandins, allylamines, and pyrimidine analogs) [13,14], emphasis was put on polyenes characterized by a large spectrum of activity induced by their unusual mechanism of action. By comparison with other classes of antifungals, polyenes do not target a specific enzyme, but rather interact selectively with sterols (especially ergosterol) in the plasma membranes of fungi, thus causing loss of membrane function, altered permeability and nutrient damage [15]. Nystatin is a broad-spectrum polyene antifungal agent derived from Streptomyces noursei, known for increased susceptibility of the fungi and for its high efficacy rate in the prophylaxis and the treatment of superficial candidiasis [16,17].

In terms of antifungal efficiency, among the use of nystatin, this work aims to evaluate certain bioactive compounds derived from natural sources, namely propolis—a resinous mixture produced by the honey bees, also known for its antifungal activity-and to scrutinize the combination therapy [18]. The novelty of the approach consists in providing chitosan film formulations with mechanical properties close to those of the soft tissues, by taking advantage of chitosan increased flexibility and bioadhesivity induced by lactic acid $\mathrm{pH}$ regulator and of the plasticizing properties of both glycerin additive and propolis bioactive agent. Moreover, to the best of our knowledge, this work is the first to demonstrate the combined effect of nystatin and propolis aqueous solution against Candida species, when administered together, under relevant simulative conditions, on vulvovaginal candidiasis. Thus, chitosan-based therapeutic formulations containing either propolis or nystatin, either their mixture were prepared as hydrogels and films, and proved to be active in the treatment of vulvovaginal and oral candidiasis, respectively.

\section{Materials and Methods}

\subsection{Materials}

Chitosan (CS), with an average molar mass of $290 \mathrm{kDa}$ and $81.6 \%$ deacetylation degree (as previously determined by viscometry, respectively by NMR analysis [19]) was provided by Merck Chemical (Saint Louis, MO, USA). L-(+)-Lactic acid (LA) and anhydrous glycerin (Gly) were purchased from Chemical Company (Iași, Romania). Nystatin (NYS) drug, internationally qualified by USP Reference Standard, with particle sizes under $50 \mu \mathrm{m}$ (Figure S1 in Supplementary Materials) was supplied by Antibiotice SA, Iași, Romania. Aqueous Propolis 30\% (w/v) (PRO) with $7.72 \mathrm{mg} / \mathrm{mL}$ polyphenols and $0.26 \mathrm{mg} / \mathrm{mL}$ flavones/flavonoids contents (spectrophotometrically determined according to Singleton et al., 1999 [20] at APHIS-DIA Laboratory, Cluj-Napoca, Romania) was purchased from Dapis Transilvania (Cluj-Napoca, Romania). All the analytical grade chemicals were used as received. Candida albicans ATCC 90028 and Candida glabrata ATCC 90030 were provided by American Type Culture Collection (Manassas, VA, USA). Yeast Nitrogen Base Agar with dextrose and Yeast Extract Peptone Dextrose Agar (YPD) were purchased from Merck Chemical (Saint Louis, MO, USA), while Sabouraud dextrose agar (SDA) was acquired from Biokar Diagnostics (Allonne, France). 


\subsection{Preparation of Chitosan Antifungal Therapeutic Formulations}

Chitosan based hydrogels or flexible films of different contents of antifungal compounds (Table 1) were prepared in several steps, as described below. First, appropriate solutions or dispersions of each individual component were obtained. Thus, a chitosan stock solution of $3 \%(w / v)$ concentration was prepared by dissolving the biopolymer in a $2 \%(w / v)$ lactic acid solution under continuous stirring at $600 \mathrm{rpm}$ and $40{ }^{\circ} \mathrm{C}$ for $24 \mathrm{~h}$. NYS $(15 \mathrm{mg})$ was dispersed in glycerin $(0.4 \mathrm{~g})$ by magnetic stirring of their mixture for $30 \mathrm{~min}$, at $40{ }^{\circ} \mathrm{C}$ and $400 \mathrm{rpm}$, and a subsequent homogenization by ultrasonication (Emmi $12 \mathrm{HC}$ ultrasonic bath, $100 \%$ ultrasonic efficiency) for $10 \mathrm{~min}$. PRO aqueous solution $(0.3 \mathrm{~mL})$ was also mixed with Gly $(0.4 \mathrm{~g})$ under stirring at $40{ }^{\circ} \mathrm{C}$ and $400 \mathrm{rpm}$ for $30 \mathrm{~min}$.

Table 1. Composition of chitosan formulations * and the thickness of the films.

\begin{tabular}{cccc}
\hline $\begin{array}{c}\text { Hydrogel/Film } \\
\text { Code }\end{array}$ & $\begin{array}{c}\text { NYS } \\
(\mathbf{m g})\end{array}$ & $\begin{array}{c}\text { PRO } \\
\text { (mL Solution/mg Solid } \\
\text { Compound) }\end{array}$ & $\begin{array}{c}\text { Films } \\
\text { Thickness } \\
(\boldsymbol{\mu m})\end{array}$ \\
\hline CS-LA & - & - & 49 \\
CS-NYS & 15 & - & 53 \\
CS-PRO & - & $0.30 / 90$ & 210 \\
CS-NYS-PRO1 & 15 & $0.15 / 45$ & 166 \\
CS-NYS-PRO2 & 15 & 220 \\
\hline
\end{tabular}

* all hydrogel formulations also contain $0.3 \mathrm{~g}$ CS (in $10 \mathrm{~mL} \%$ LA solution) and $0.4 \mathrm{~g}$ Gly; the films were obtained by hydrogel drying and each formulation has a composition identical to the corresponding hydrogel, without water.

CS-based formulations charged either with NYS (CS-NYS) or with PRO (CS-PRO) were obtained by adding $10 \mathrm{~mL}$ of the stock solution of chitosan over each of their mixtures with Gly and stirring for $1 \mathrm{~h}$ at room temperature.

Two chitosan formulations, CS-NYS-PRO1 and CS-NYS-PRO2, containing both antifungal agents in different ratios (PRO/NYS $=3 / 1$ or $6 / 1 w / w)$ were prepared by subsequently adding calculated amounts of PRO aqueous solution and of $10 \mathrm{~mL}$ of the stock solution of chitosan onto NYS-Gly dispersion (previously prepared as described above) and stirring at room temperature till homogenization was achieved (about $1 \mathrm{~h}$ ). All the prepared hydrogels were characterized by $\mathrm{pH}$ values of $3.85 \pm 0.02$, as measured by using a HANNA instruments HI8417pH meter (Amorim, Portugal).

An identical set of hydrogels was separately prepared and each sample was poured into a $5 \mathrm{~cm}$ diameter Petri dish. The drying at room temperature yielded transparent CS-NYS, CS-PRO, CS-NYS-PRO1 and CS-NYS-PRO2 films of micrometric thickness (measured with a Dial Thickness Gauge 7301 handheld micrometer-Mitoyuto Corporation, Kangagawa, Japan; accuracy of $1 \mu \mathrm{m}$ ), depending on composition (Table 1). For analytical purposes, uncharged chitosan hydrogel and film (CS-LA) were also prepared.

\subsection{Methods of Characterization}

\subsubsection{Structural and Morphological Characterization of Film Formulations}

Fourier transform (FTIR) spectra of film formulations were registered by using a Bruker Vertex 70 spectrophotometer (Bruker Optics, Ettlingen, Germany), in ATR (Attenuated Total Reflectance) mode (wavelength range of $4000-600 \mathrm{~cm}^{-1}$, resolution of $2 \mathrm{~cm}^{-1}$ and 64 scans at room temperature). Scanning electron microscopy (SEM) images of cross-sections of the prepared films were obtained on an FEI QUANTA 200 electron scanning microscope (Brno, Czech Republic) with a resolution of $4 \mathrm{~nm}$ at $30 \mathrm{kV}$. The drug dispersion in the films was visualized on a Leica Microsystems Polarized Optical Microscope (Wetzlar, Germania).

\subsubsection{Mechanical Properties of the Films}

Tensile strength, elongation at break, and Young's modulus were determined on an Instron 3365 equipment (Norwood, MA, USA) with two columns and a $500 \mathrm{~N}$ force cell. Dumbbell-shaped samples for each film were cut using a press (length/width/active length $=50 / 4.1 / 35 \mathrm{~mm}$ ) and the uniaxial stress-strain curves of the samples occurs at 
$50 \mathrm{~mm} / \mathrm{min}$ elongation speed. The stress $\left(\sigma_{\mathrm{b}}\right)$ and strain $\left(\varepsilon_{\mathrm{b}}\right)$ at break were calculated according to Equations (1) and (2), respectively:

$$
\begin{gathered}
\sigma_{\mathrm{b}}(\mathrm{MPa})=\mathrm{F}_{\mathrm{b}} / \mathrm{A} \\
\varepsilon_{\mathrm{b}}(\%)=\Delta \mathrm{l} / \mathrm{l}_{0} \times 100
\end{gathered}
$$

where $F_{b}$ is the breaking force, $A$ is the cross-sectional area of the sample at time $t, l_{0}$ represents the initial length, and $\Delta \mathrm{l}$ represents the elongation at traction. Based on the specific deformation curve, the modulus of elasticity for each film was also determined as the ratio between the stress and the tensile deformation (1\%).

\subsubsection{Swelling Behavior of Film Formulations in Simulated Conditions}

$1 \mathrm{~cm}^{2}$ of film samples were dried in an oven at $40{ }^{\circ} \mathrm{C}$ till constant weight, were immersed in $50 \mathrm{~mL}$ phosphate buffered saline (PBS) solution of $\mathrm{pH} 7.4$ and were placed in an Orbital Shaker-Incubator ES-20/60 (Biosan-Riga, Latvia) at $37^{\circ} \mathrm{C}$ and $80 \mathrm{rpm}$. At predetermined time intervals, the samples were removed from the immersion medium; the excess PBS solution was removed from the surface by buffering with filter paper and the samples were weighed. The kinetics of the film swelling was evaluated by a gravimetric method, according to Equation (3):

$$
\mathrm{S}_{\mathrm{t}}(\mathrm{g} / \mathrm{g})=\left(\mathrm{w}_{\mathrm{t}}-\mathrm{w}_{0}\right) / \mathrm{w}_{0}
$$

where $S_{t}(w / w)$ represents the value of swelling capacity at time $t(\min ), w_{0}$ is the initial mass of the dried sample, and $w_{t}$ is the mass of the sample at time $t$ after immersion in PBS. The data were plotted by using the average values of the three determinations for each film formulation. To establish the equilibrium swelling capacity, the experimental data were also analyzed by applying a pseudo-second order kinetic model (PSO), expressed by Equation (4) [21,22]:

$$
\mathrm{S}_{\mathrm{t}}(\mathrm{g} / \mathrm{g})=\mathrm{k}_{\mathrm{s}} \times \mathrm{S}_{\mathrm{e}}^{2} /\left(1+\mathrm{k} \times \mathrm{S}_{\mathrm{e}} \times \mathrm{t}\right)
$$

where $S_{t}(g / g)$ represents the swelling capacity at contact time $t(\min ), k_{s}$ is the constant of the swelling rate and $S_{e}$ represents the theoretical swelling capacity at equilibrium time.

The swelling dynamics (diffusion-controlled or relaxation-controlled) of the films into PBS up to $5 \mathrm{~h}$ was evaluated using the Equation (5) [23,24], adapted after Korsmeyer and Peppas (K-P) model [25]:

$$
\mathrm{F}=\mathrm{S}_{\mathrm{t}} / \mathrm{S}_{\mathrm{e}}=\mathrm{k}_{\mathrm{p}} \times \mathrm{t}^{\mathrm{n}}
$$

where $F$ is the swelling fraction, $S_{t}$ and $S_{e}$ are the swelling capacities at time $t$, and at equilibrium, respectively; $\mathrm{k}_{\mathrm{p}}$ is a constant dependent on the polymeric network; $\mathrm{n}$ is the diffusion parameter of aqueous PBS in the formulation film [23].

The diffusion parameter value is characterizing the diffusion mechanism of aqueous molecules in the film formulations: $\mathrm{n}<0.5$ implies a Fickian diffusion-controlled mechanism; $0.5<\mathrm{n}<1$ suggests anomalous non-Fickian diffusion; $\mathrm{n}=1$ indicates a relaxation-controlled water transport and $n>1$ represents a supercase II of diffusion [22]. The experimental data were processed by using SCILAB 6.1.0 software.

\subsubsection{In Vitro Nystatin/Propolis Release from Film Formulations}

Pre-weighed dried samples of antifungal chitosan hydrogels were immersed each in $50 \mathrm{~mL}$ of neutral PBS solution (pH 7.4), placed in an Orbital Shaker-Incubator ES-20/60 (Biosan-Riga, Latvia) and maintained at $37^{\circ} \mathrm{C}$ and $80 \mathrm{rpm}$. At predetermined time intervals, $0.5 \mathrm{~mL}$ were extracted from each solution (subsequently being replaced with the same volume of initial buffer solution) and were spectrophotometrically analyzed using a double-beam UV-VIS spectrophotometer Hitachi U-3900 (Hitachi High-Tech Europe $\mathrm{GmbH}-$ Krefeld, Germania). The drugs concentrations in solution were established based on previously performed calibration curves and the release efficiency was evaluated as 
a function of time. Nystatin characteristic absorption bands were identified at 293, 305, and $320 \mathrm{~nm}$. The calibration curves were plotted and the concentrations were determined by using the band at $320 \mathrm{~nm}$ for nystatin, and the specific absorption band at $284 \mathrm{~nm}$ for propolis.

In order to determine the drugs release mechanism (Fickian or non-Fickian diffusion), the experimental data were mathematically fitted (SCILAB 6.1.0 software) using the semi-empirical equation (Equation (6)) proposed by Korsmeyer and Peppas (1981), which describes both in vitro drug release from thin plane films and the stability behavior [25]:

$$
\mathrm{M}_{\mathrm{t}} / \mathrm{M}_{\infty}=\mathrm{k} \times \mathrm{t}^{\mathrm{n}}
$$

where $M_{t} / M_{\infty}$ refers to the fractional drug release at time $t ; M_{t}$ and $M_{\infty}$ are the total amount of drug released at time $\mathrm{t}$ and at infinite time, respectively; $\mathrm{k}$ represents the transport constant, $\mathrm{n}$ is the diffusion exponent that indicates the type of drug release transport (Quasi-Fickian diffusion for $\mathrm{n}<0.5$, Fickian diffusion for $\mathrm{n}=0.5$, non-Fickian transport for $n>0.5$, Case II transport for $n=1$, and supercase II transport for $n>1$ ) [26].

\subsubsection{Dynamic Vapor Sorption Measurements}

The water vapor sorption capacity of the hydrogel formulations was determined in dynamic regime by using a fully automated gravimetric device IGAsorp provided by Hiden Analytical (Warrington, UK). The samples were placed in a special container and dried at $25^{\circ} \mathrm{C}$ using a nitrogen flow of $250 \mathrm{~mL} / \mathrm{min}$ until their weights reached equilibrium at a relative humidity, $\mathrm{RH}$, less than $1 \%$. Subsequently, the $\mathrm{RH}$ was gradually increased from 0 to $90 \%$, with humidity steps of 10\% (at pre-established equilibrium time between $40-60 \mathrm{~min}$ ) and the sorption equilibrium was registered for each step in the sorption curve. The RH was further decreased and desorption curves were also registered. To evaluate the specific surface area, Brunauer-Emmett-Teller kinetic model (BET) was applied by modeling the sorption isotherms registered under dynamic conditions, according to Equation (7) [27,28]:

$$
\mathrm{W}=\mathrm{W}_{\mathrm{m}} \times \mathrm{C} \times \mathrm{RH} /(1-\mathrm{RH})(1-\mathrm{RH}+\mathrm{C} \times \mathrm{RH})
$$

where $\mathrm{W}$ and $\mathrm{W}_{\mathrm{m}}$ represent the weight of absorbed water and the weight of water forming a monolayer, respectively; $\mathrm{C}$ is the sorption constant and $\mathrm{RH}$ represents the relative humidity.

The average pore size, $r_{\mathrm{pm}}$, was estimated by applying Barrett, Joyner, and Halenda model (BJH) [28], based on calculation methods for cylindrical pores, in accordance with Equations (8) and (9):

$$
\begin{gathered}
\mathrm{V}_{\mathrm{liq}}=\mathrm{n} / 100 \times \rho_{\mathrm{a}} \\
\mathrm{r}_{\mathrm{pm}}=2 \mathrm{~V}_{\mathrm{liq}} / \mathrm{A}
\end{gathered}
$$

where $\mathrm{V}_{\text {liq }}$ is the liquid volume; $\mathrm{n}$ is the absorption percentage; $\rho_{\mathrm{a}}$ represents the adsorbed phase density and A is the specific surface area determined by BET method.

\subsubsection{Rheological Properties of the Hydrogels}

Rheological measurements were performed on a Physica MCR 301 Stress Controlled Rotational Rheometer (Anton Paar Company, Graz, Austria) with cone-plate geometry (50 mm diameter, an angle of $1^{\circ} / 99 \mu \mathrm{m}$ truncation). The viscoelastic properties were analyzed based on the dynamic oscillatory and temperature sweep measurements. Preliminary tests were performed at $10 \mathrm{rad} / \mathrm{s}$ in the $0.1-200 \%$ deformation range with a constant shear displacement $\gamma$ of $10 \%$. The dynamic oscillatory tests were conducted at constant temperature of $35 \pm 0.1{ }^{\circ} \mathrm{C}$ (accurately controlled by Peltier heating system) and angular frequency $(\omega)$ in the range of $0.05 / 0.1-100 \mathrm{rad} / \mathrm{s}$. The elastic modulus, $\mathrm{G}^{\prime}$, which represents the solid-like component of viscoelastic behavior of the material, the viscous modulus, $\mathrm{G}^{\prime \prime}$, representative for liquid-like component were investigated as functions of the angular frequency $\omega(\mathrm{rad} / \mathrm{s})$. 
The viscoelastic behavior was evaluated also by determining the tangent of $\delta$ phase angle (Equation (10)) and the complex viscosity (Equation (11)), which is related to complex modulus as described by Equation (12) [29]:

$$
\begin{gathered}
\tan \delta=G^{\prime \prime} / G^{\prime} \\
\eta^{*}=G^{*} / \omega \\
G^{*}=G^{\prime}+i G^{\prime \prime}
\end{gathered}
$$

where $\delta$ is the phase angle (a relative measure for the visco-elastic properties); $G^{\prime}$ and $G^{\prime \prime}$ are the elastic and viscous moduli; $\eta^{*}$ is the complex viscosity and $G^{*}$ represents the complex modulus, which is a complex number with i representing an imaginary number [30].

Temperature sweep measurements were realized at a constant shear rate of $10 \mathrm{~s}^{-1}$, over the temperature range $5-40{ }^{\circ} \mathrm{C}$ with a heating rate of $2{ }^{\circ} \mathrm{C} / \mathrm{min}$. After loading and before measurement, a $5 \mathrm{~min}$ rest time for each sample was allowed to ensure stress relaxation and temperature equilibration. The viscosity of the hydrogels $(\eta)$ was evaluated as a function of

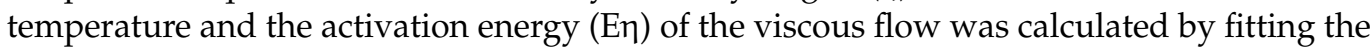
experimental data with Arrhenius exponential equation (Equation (13)), using a logarithmic form according to Equation (14). The natural logarithm of $\eta$ was plotted as function of $1 / \mathrm{T}\left(\mathrm{K}^{-1}\right)[31]$ :

$$
\begin{gathered}
\eta=A \exp (E \eta / R T) \\
\ln \eta=\ln A+E \eta / R T
\end{gathered}
$$

where $\eta$ is viscosity of the hydrogels; A represents the Arrhenius factor (a constant associated with the nature of the liquid); $\mathrm{E \eta}$ is the viscous flow activation energy; $\mathrm{R}$ is the molar gas constant $\left(1.9872 \mathrm{cal} \cdot \mathrm{K}^{-1} \cdot \mathrm{mol}^{-1}\right)$ and $\mathrm{T}$ is the temperature $(\mathrm{K})$.

\subsubsection{Antifungal Activity of the Hydrogel}

The prepared chitosan formulations (CS-NYS, CS-PRO, CS-NIS-PRO1 and CS-NISPRO2) as well as CS-LA solution were evaluated for antifungal activity against two reference strains from the American Type Culture Collection (Candida albicans and Candida glabrata), which are the main pathogens responsible for invasive candidiasis. Both Candida strains were stored in $20 \%$ glycerin at $-80{ }^{\circ} \mathrm{C}$. Prior to testing, each strain was refreshed on Sabouraud dextrose agar (SDA) and incubated for $48 \mathrm{~h}$ at $30^{\circ} \mathrm{C}$. The yeast strains were used when a maximal number of conidia were formed.

The antifungal activity of CS-based hydrogels was evaluated by using the agar disk diffusion method. Microbial suspensions were prepared in sterile saline solution to obtain an optical turbidity comparable to that of the $0.5 \mathrm{McF}$ arland standards (each suspension contains $1 \times 108$ colony-forming units $/ \mathrm{mL}(\mathrm{CFU} / \mathrm{mL}))$. Volumes of $0.2 \mathrm{~mL}$ from each inoculum were taken and spread onto Yeast Nitrogen Base Agar with dextrose previously poured in Petri dishes. After the drying of the medium surface, each sample of chitosan hydrogels $(10 \mu \mathrm{L})$ was added. The antifungal properties of the tested hydrogels were determined by measuring fungal growth inhibition, under standard conditions (after incubation for $48 \mathrm{~h}$ at a temperature of $30^{\circ} \mathrm{C}$ ). All experiments were performed in triplicate, in order to verify the final results. The diameter of the inhibition zone around the hydrogel samples was finally measured using a caliper with digital display.

\subsubsection{Time-Kill Assay}

Time-kill experiments were performed on Candida albicans ATCC MYA-2876 (SC5314 wild type) using a slightly modified previously described method [32]. Thus, a synthetic vagina-simulative medium (SVSM) was prepared $[33,34]$ to assure specific biomimetic conditions. Before performing the tests, the strain was sub cultured at least twice and grown for $24 \mathrm{~h}$ at $35^{\circ} \mathrm{C}$ on SDA plates.

To examine the rate of killing, from each strain, a 5 McFarland suspension in SVSM was prepared and adjusted to $1.24 \times 10^{7} \mathrm{CFU} / \mathrm{mL}$ using the TC20 automated cell counter 
(Bio-rad, Hercules, CA, USA). Subsequently, equal volumes of yeast cell suspension and chitosan hydrogels dispersions in SVSM were mixed and incubated at $36 \pm 1^{\circ} \mathrm{C}$, to obtain final mixtures for each compound. A drug free control was also prepared by mixing equal volumes of yeast suspension and SVSM. At predetermined time intervals $(0,6,12$, and $24 \mathrm{~h}), 1000 \mu \mathrm{L}$ aliquot from each test and control tube was serially diluted in sterile distilled water, plated onto YPD agar medium and incubated $48 \mathrm{~h}$ at $36 \pm 1{ }^{\circ} \mathrm{C}$, in order to evaluate the number of CFU $/ \mathrm{mL}$. The reproducible detection limit for colony counts is $10^{1} \mathrm{CFU} / \mathrm{mL}$. All time-kill curves were plotted for the binary mixture (log10 CFU/mL against time) and the assays were conducted in duplicate and on two separate occasions.

\section{Results and Discussions}

\subsection{Therapeutic Formulations Design and Preparative Protocol}

Hydrogels and films formulations are considered to be the most suitable therapeutic systems for the treatment of superficial candidiasis, as they can cover a larger area for the administration of antifungal agents, offering, at the same time, physical protection [35]. Although, chitosan-based hydrogels with propolis and nystatin (among others active principles) were evaluated by Perchyonok et al. (2012-2014) as restorative materials for increasing the dentin bond strength capacity and for oral mucositis treatment [35-38], this work is a first report on evaluating and demonstrating the antifungal effect of nystatin and/or propolis loaded chitosan systems under relevant simulative conditions on vulvovaginal candidiasis. In addition, the use of L-lactic acid for chitosan solubilization and of an aqueous propolis extract in the preparation of chitosan-based nystatin and/or propolis delivery systems are for the first time investigated.

Glycerin was selected for nystatin dispersion and as an additive in antifungal formulations, having in mind its ability to solubilize lipophilic drugs in w/o emulsions, to promote local delivery of the drugs in topical and mucosal applications [39], as well as to act as a plasticizer for chitosan $[40,41]$.

The dissolution of chitosan was performed in lactic acid solution, as it has been shown to induce to the CS formulations mechanical properties suitable for their use on soft tissues, by increasing flexibility (for the films) and bioadhesion (for hydrogels), as opposed to acetic acid [42]. Although DL-lactic acid was used in most pharmaceutical applications, we choose to use L-(+)-lactic acid, primarily because it is a known compound of human metabolism and secondly because it was proven to lower the tensile strength and to increase elongation at break of chitosan films [43]. The physicochemical characterization of film formulations (mechanical properties, swelling and drug release in simulative medium) was done to demonstrate their usefulness as buccal drug delivery systems. As the chitosan hydrogels were characterized by $\mathrm{pH}$ values of $3.85 \pm 0.02$, close to the value of vaginal fluids ( $\mathrm{pH}=4.2$ [33]), they were tested as therapeutic systems under simulative conditions in the therapy of vulvovaginal candidiasis.

\subsection{Structural Characterization}

The structure of nystatin (NYS), its ${ }^{13} \mathrm{C}$ NMR and ${ }^{1} \mathrm{H}$ NMR spectra are given in Supplementary Materials, Figures S2 and S3, proving the high purity of the polyene macrolide [44-46]. The structure of chitosan and a comparison between the FTIR spectra of pristine chitosan powder and of the film prepared by its dissolving in aqueous lactic acid solution and drying are presented in Supplementary Materials, Figures S4 and S5, respectively. Polyphenols and flavonoids (not structurally identified) are present in propolis (PRO) solubilized in aqueous media, in the proportion mentioned in the experimental part, as specified by the supplier.

Figure 1 compares the characteristics FTIR absorptions of the drugs (NYS and PRO), CS-LA matrix and of the resulted film formulations (CS-NYS and CS-PRO, as typical exemples). As no visible modifications were found in the region of asymmetric and symmetric C-H stretching vibrations (2900-2800 $\left.\mathrm{cm}^{-1}\right)$, for the sake of clarity, this region is not represented in Figure 1. NYS (Figure 1a) is characterized by a large number of 
hydroxyl groups whose stretching vibrations are found in the range $3200-3700 \mathrm{~cm}^{-1}$, overlapping with the vibrations of the $\mathrm{NH}_{2}$ group. Other characteristic bands are found at $1706 \mathrm{~cm}^{-1}$ (C=O stretching vibrations from ester and carboxylic acid groups), at $1575 \mathrm{~cm}^{-1}$ and $846 \mathrm{~cm}^{-1}$ (typical vibrations corresponding to the polyenes $C=C$ units), in the intervals $1440-1320 \mathrm{~cm}^{-1}$ (deformation vibrations of $\mathrm{CH}_{3}$ ) and $1180-1000 \mathrm{~cm}^{-1}$ (vibrations of the $\mathrm{C}-\mathrm{C}-\mathrm{O}$ and $\mathrm{C}-\mathrm{O}-\mathrm{C}$ groups, respectively) $[47,48]$.

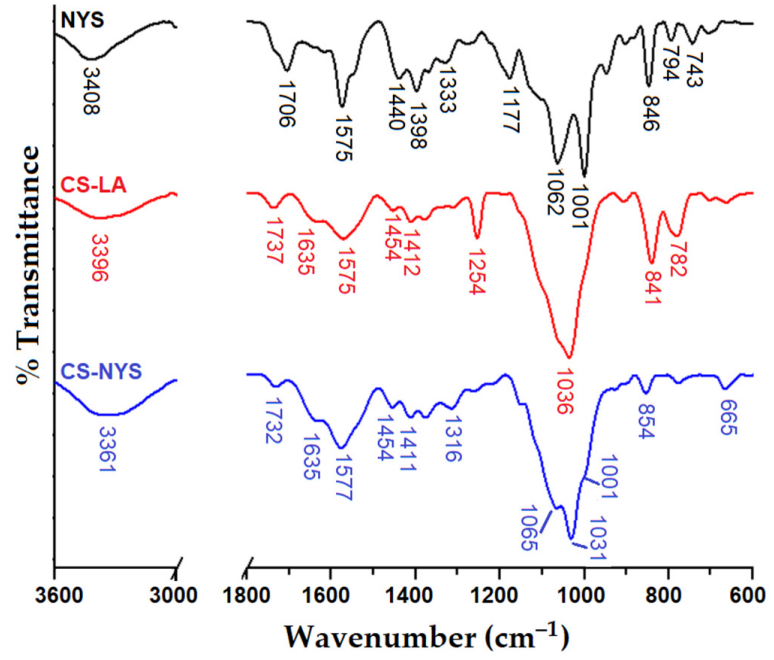

(a)
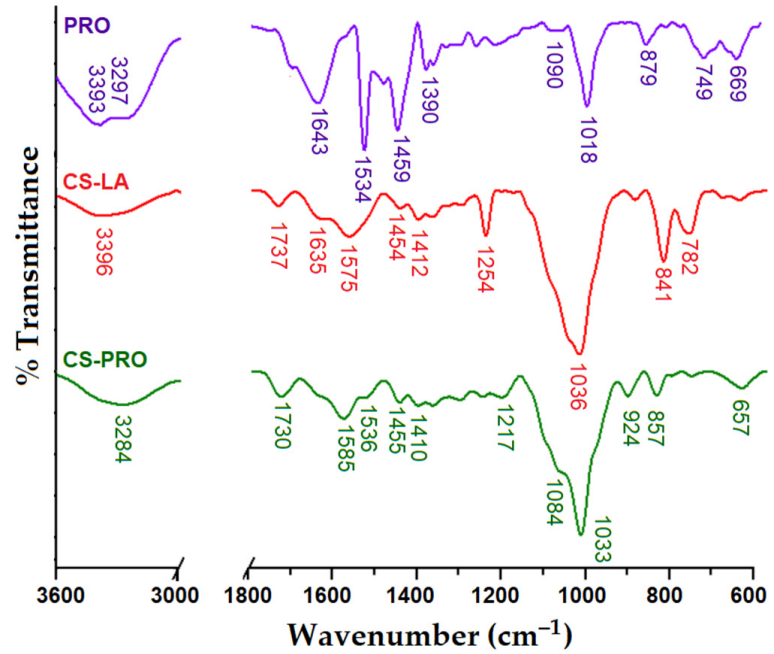

(b)

Figure 1. FTIR spectra of the individual components and: CS-NYS film (a); CS-PRO film (b).

Propolis (PRO) chemical composition is well-known for polyphenols and flavonoids content, with characteristic absorption bands clearly evidenced in the FTIR spectrum (Figure 1b). Wide absorption band centered at $3395 \mathrm{~cm}^{-1}$ is attributed to the $\mathrm{OH}$ stretching vibration of phenolic compounds and to the formation of inter(intra)molecular hydrogen bonds. Specific to PRO, the following absorption bands are identified: $1643 \mathrm{~cm}^{-1}(\mathrm{C}=\mathrm{O}$ flavonoid carbonyl stretching vibration), $1534 \mathrm{~cm}^{-1}$, and $1459 \mathrm{~cm}^{-1}$ (aromatic rings of polyphenols and $\mathrm{C}=\mathrm{C}$ groups of flavonoids) $[49,50], 1390 \mathrm{~cm}^{-1}$ (C-O stretching vibrations and $\mathrm{O}-\mathrm{H}$ deformation, specific to phenols), $1018 \mathrm{~cm}^{-1}$ (strong absorption band of $\mathrm{C}-\mathrm{O}$ esters asymmetric stretching vibration), $879 \mathrm{~cm}^{-1}, 749 \mathrm{~cm}^{-1}$, and $669 \mathrm{~cm}^{-1}$ (medium absorption bands corresponding to the out-of-plane deformation vibration of phenol $\mathrm{CH}$, and $\mathrm{CH}_{2}$ rocking of hydrocarbons) [50,51].

The chitosan film obtained from its aqueous solution (CS-LA) reveals the absorption band at $1737 \mathrm{~cm}^{-1}$ due to the carboxylate $\left(\mathrm{COO}^{-}\right)$groups provided by lactic acid and a broad band centered at $1575 \mathrm{~cm}^{-1}$ that was attributed to the deformation vibrations of protonated amine groups (superimposed over amide vibrations), mainly confirming the electrostatic interactions between protonated chitosan amine groups and carboxylate ions $\left(\mathrm{NH}_{3}{ }^{+-} \mathrm{OOCCH}(\mathrm{OH}) \mathrm{CH}_{3}\right)$ [52]. The presence of lactic acid determines the appearance of the band at $1454 \mathrm{~cm}^{-1}$, associated with the $\mathrm{CH}_{3}$ asymmetric deformation vibrations in its structure [53]. Moreover, the absorption band centered at $1036 \mathrm{~cm}^{-1}$ indicates the presence of stretching vibrations of the $\mathrm{C}-\mathrm{O}$ groups of lactic acid, overlapped with the $\mathrm{C}-\mathrm{O}-\mathrm{C}$ vibrations of chitosan [54]. The asymmetric $\mathrm{C}-\mathrm{O}$ stretching vibrations are found at $1254 \mathrm{~cm}^{-1}$, while the $\mathrm{C}-\mathrm{C}$ stretching and $\mathrm{C}=\mathrm{O}$ deformation vibrations from the lactic acid structure appear at $841 \mathrm{~cm}^{-1}$ and $782 \mathrm{~cm}^{-1}$ [55]. The lack of a new amide absorption band at about $1540 \mathrm{~cm}^{-1}$ indicates the absence of covalently grafting of LA on CS [56].

FTIR spectra of the antifungal films of nystatin (CS-NYS) and propolis (CS-PRO) embedded into chitosan matrix can be observed in the bottom of the Figure 1a,b, respectively. Due to the structural similarities, the characteristic bands of nystatin and/or propolis are overlapping with polysaccharide bands. In addition, the low content of the drugs into the CS formulations makes rather difficult their identifications in the spectra of the corresponding formulations. However, an in-depth comparison between the spectra of the 
intermediates and of the corresponding film formulations reveals the presence of the drugs into CS matrix. Thus, as a consequence of the increased number of $\mathrm{OH}$ groups coming from NYS and PRO components, and of the larger diversity of hydrogen bonding, the typical broad $\mathrm{O}-\mathrm{H}$ absorption bands in the region $3600-3200 \mathrm{~cm}^{-1}$ have higher intensities in the spectra of both CS-NYS and CS-PRO film formulations, as compared to that of CS-LA matrix, and are shifted at different wavenumbers, as compared with the spectra of the individual components. The embedment of the active principles in the polysaccharide matrix induced a slight displacement of the characteristic $\mathrm{C}=\mathrm{O}$ lactate band from 1737 (CS-LA) to $1732 \mathrm{~cm}^{-1}$ (CS-NYS) and $1730 \mathrm{~cm}^{-1}$ (CS-PRO). Moreover, some of the drug bands are also visible in the spectra of the corresponding film formulations. Thusly, CS-NYS spectrum shows broader and a more intense band at $1577 \mathrm{~cm}^{-1}$ due to the superposition of the $C=C$ band of NYS located at $1575 \mathrm{~cm}^{-1}$ over amide/amine bands of CS; the bands at 1062 and $1001 \mathrm{~cm}^{-1}$ of NYS are visible as shoulders $\left(1065\right.$ and $\left.1001 \mathrm{~cm}^{-1}\right)$ in the region of the C-O-C vibrations of CS-NYS spectrum. Similar traces of PRO are visible in the spectrum of CS-PRO film (e.g., the appearance of a shoulder at $1536 \mathrm{~cm}^{-1}$ induced by the contribution of the aromatic ring vibrations of polyphenols and the displacement of the amide/protonated amine band of CS from $1575 \mathrm{~cm}^{-1}$ to $1585 \mathrm{~cm}^{-1}$ ).

\subsection{Films Morphology}

The morphology of chitosan antifungal films (CS-NYS, CS-PRO, CS-NYS-PRO1, and CS-NYS-PRO2) was examinated by reference to CS-LA film on SEM images of their crosssections (Figure 2). The CS-LA sample presents a homogeneous, dense and cohesive structure, characteristic for unmodified chitosan films. The addition of nystatin to the polysaccharide matrix (CS-NYS) did not induce major morphological changes of the film. However, besides the dense and compact morphology, the dispersion of NYS as white nanoparticles in the chitosan matrix can be distinguished. The downsizing of NYS crystallites (with initial dimensions up to $50 \mu \mathrm{m}$ as seen in Figure S1, Supplementary Materials), as an effect of ultrasonication in glycerin and incorporation into the chitosan matrix can be noticed. The introduction of propolis into the chitosan matrix induces film thickening, as compared to CS-LA and CS-NYS, and visible morphological changes. Most are evidenced for CS-PRO and CS-NYS-PRO2 samples, due to the higher amount of propolis. Thus, CS-PRO presents an homogenous wavy organized structure, while CS-NYS-PRO2 shows a discontinuous morphology with phase separation between chitosan and glycerin/propolis plasticizers. Similar morphology was observed when sorbitol was used as a plasticizer for chitosan films [57].

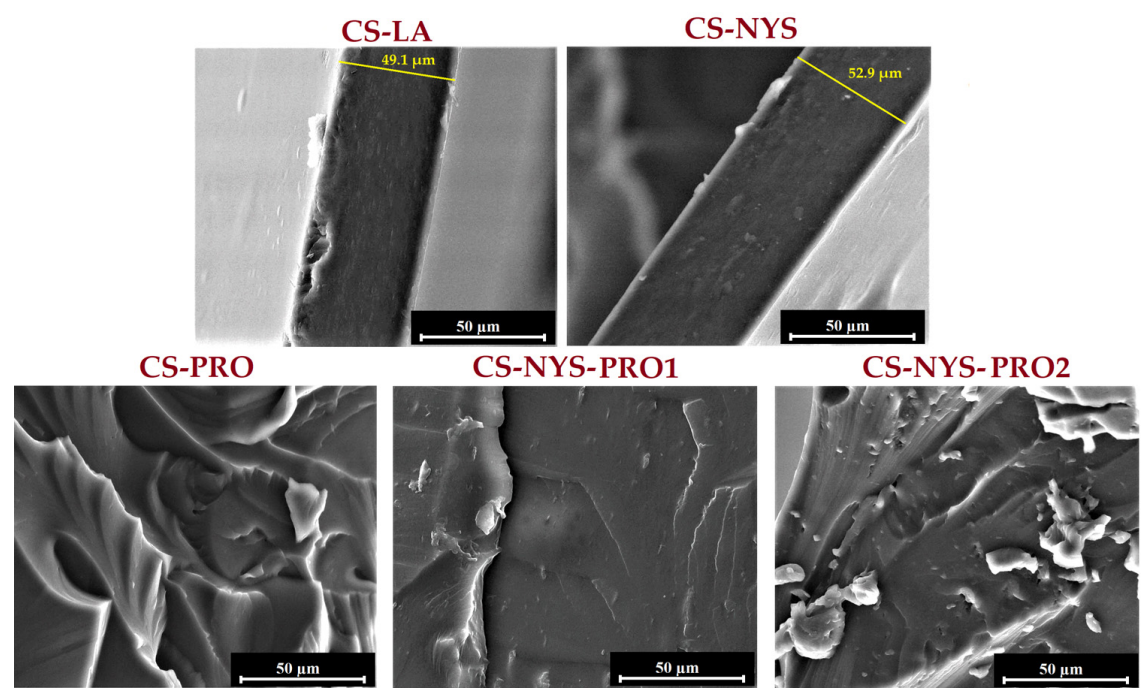

Figure 2. Scanning electron microscopy images of the cross-sections of CS-LA, CS-NYS, CS-PRO, CS-NYS-PRO1 and CS-NYS-PRO2 films. 
The morphology of the prepared transparent films was also investigated by polarized light microscopy (Figure 3). The image obtained for CS-LA film is typical for a partially crystalline polymer with crystalline domains embedded in the amorphous ones. Even if nystatin is known for its insolubility in aqueous medium and its tendency to form aggregates, the uniform dispersion of the polyene in the CS-NYS, CS-NYS-PRO1 and CS-NYS-PRO2 chitosan films is easily visible.

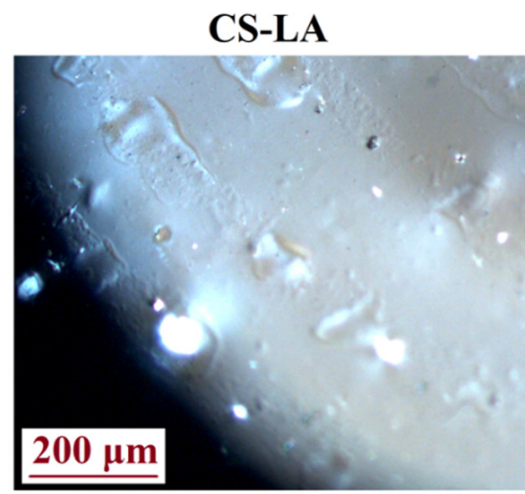

CS-NYS-PRO1

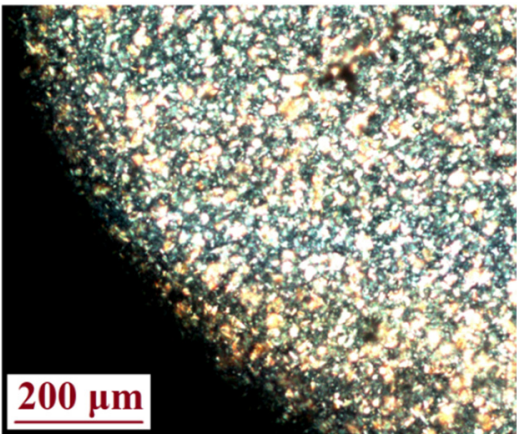

CS-NYS

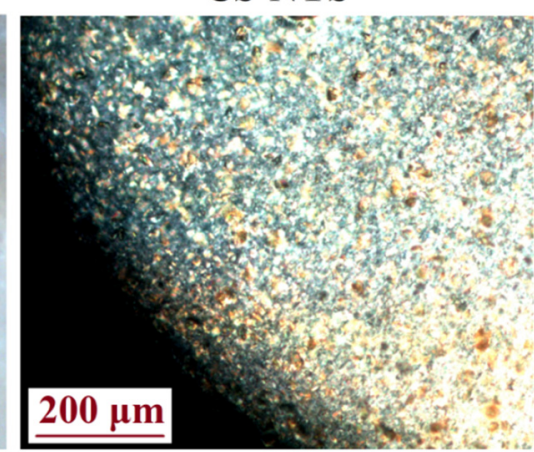

CS-NYS-PRO2

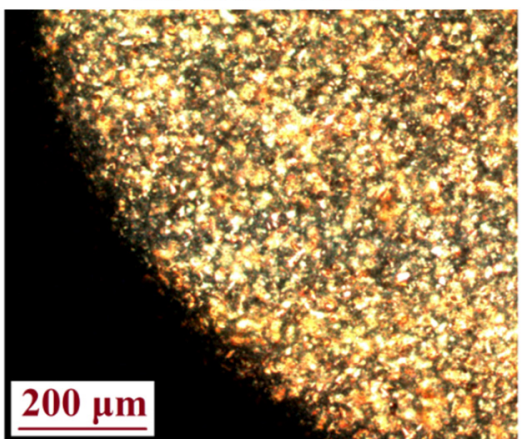

Figure 3. Polarized light microscopy images of CS-LA, CS-NYS, CS-NYS-PRO1 and CS-NYS-PRO2 films surface.

\subsection{Mechanical Properties of Films}

Chitosan with nystatin and/or propolis hydrogels were dried and the mechanical properties of the resulted micronic films (see the thickness in Table 1) were evaluated in order to prove potential similarities with the mechanical properties of the human soft tissues and the suitability of their application in the treatment of oral candidiasis. Mechanical properties of the antifungal films were investigated based on the characteristic stressstrain curves (Figure S6 in Supplementary Materials). The tensile strength at break $\left(\sigma_{\mathrm{b}}\right)$, elongation at break $\left(\varepsilon_{\mathrm{b}}\right)$ and modulus of elasticity $(\mathrm{Y})$ were determined and evaluated by comparison with the those of CS-LA film (Table 2). All charged chitosan films are much ductile, contrary to CS-LA sample. They present more than 10 folds and about 2 order of magnitude decrease of the tensile strenght (from 73.3 MPa to 3.0-8.6 MPa) and of the Young's modulus (from 9.310 to $0.044-0.025 \mathrm{MPa}$ ), respectively, as well as a considerable increase of the elongation at break (from 7.7 to $68.9-113.9 \%$ ). These characteristics of the charged CS films are mainly due to the plasticizing action synergetically induced by GLY and PRO to the CS matrix. Similar behavior was reported by others for Gly-CS mixtures and was explained by the formation of hydrogen bonds between the $\mathrm{OH}$ groups of the triol compound and the protonated amino groups $\left(\mathrm{NH}^{3+}\right)$ of the polysaccharide, leading to the reorganization of chitosan chains and formation of an orderly structure [40,41]. NYS alone provided to the film the highest elasticity (the higher elongation at break was registered for CS-NYS film), while PRO seems to provide most pronounced plasticizing effect (lower values of the three studied mechanical properties were registered for all PRO containing films). Propolis was also proposed as a bioplasticizer for starch [51]. All the 
prepared antifungal chitosan films are characterized by increased elasticity, malleability and mechanical properties close to those of the soft tissues (Young's modulus of soft biological tissues has values lower than $<1 \mathrm{MPa}$ [58]), being suitable for application on buccal mucosa.

Table 2. Mechanical properties * of CS films.

\begin{tabular}{cccc}
\hline Film Code & $\begin{array}{c}\boldsymbol{\sigma}_{\mathbf{b}} \\
\mathbf{( M P a )}\end{array}$ & $\begin{array}{c}\boldsymbol{\varepsilon}_{\mathbf{b}} \\
\mathbf{( \% )}\end{array}$ & $\begin{array}{c}\mathbf{Y} \\
(\mathbf{M P a})\end{array}$ \\
\hline CS-LA & 73.3 & 7.7 & 9.310 \\
CS-NYS & 8.6 & 113.9 & 0.044 \\
CS-PRO & 7.5 & 88.1 & 0.031 \\
CS-NYS-PRO1 & 5.4 & 74.8 & 0.036 \\
CS-NYS-PRO2 & 3.0 & 68.9 & 0.025 \\
\hline
\end{tabular}

* tensile strength at break- $\sigma_{\mathrm{b}}$; elongation at break- $\varepsilon_{\mathrm{b}} ;$ Young's modulus-Y.

\subsection{Swelling Capacity of Films}

Knowing that the excessive hydration of the films might lead to decreased bioadhesion at the interface with buccal mucosa [59], the swelling capacities of chitosan films charged with nystatin and/or propolis were evaluated in PBS, at physiological oral $\mathrm{pH} 7.4$ and $37^{\circ} \mathrm{C}$. It should be noted that the pure chitosan film (CS-LA) was completely dissolved in the aqueous medium, while all chitosan charged films were recovered after $24 \mathrm{~h}$ contact with PBS solution as self-standing swollen hydrogels. Their increased hidrodynamic stability can be explained by the effect of the electrostatic interactions and/or intermolecular hydrogen bonding between polysacharide and the drug molecules. Figure 4 shows the $5 \mathrm{~h}$ swelling kinetics of the charged CS films and the plots for PSO and K-P kinetic models. For CS-NYS sample a rapid increase of the swelling capacity to more than $500 \%$ the first $2 \mathrm{~min}$, followed by an importand decrease of the swelling rate was registered. The film reaches swelling degrees of 618 and $751 \%$ after 5 and 24 h, respectively of immersion in PBS (Table S1).

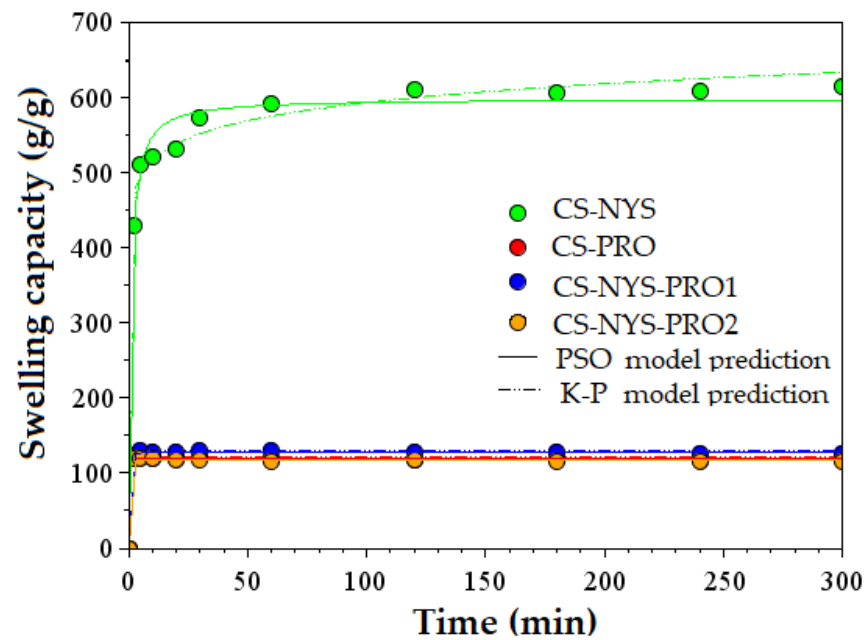

Figure 4. Swelling kinetics of chitosan films with nystatin (CS-NYS), propolis (CS-PRO), and both nystatin and propolis (CS-NYS-PRO1, CS-NYS-PRO2).

CS films charged with propolis (CS-PRO, CS-NYS-PRO1 and CS-NYS-PRO2) presented much lower capacities of welling, as compared to CS-NYS sample, probably due to the chemical crosslinking of the polyphenols found in the natural antifungal agent to the amino groups of the chitosan. All these three samples indicated almost identical swelling behavior, with an immediate (first $2 \mathrm{~min}$ ) increase to practical maximum swelling capacity, between 117 and $122 \%$ (Table S1).

The kinetic parameters of the PSO and K-P models are given in Table S1 for all drug charged CS films. The theoretical equilibrium swelling capacity $\left(S_{e}\right)$ values are close to those of the experimental swelling capacity after $5 \mathrm{~h}$, except the CS-NYS sample. The diffusion 
exponents, $\mathrm{n}$, have values lower than 0.5 , suggesting a Fickian diffusion-controlled swelling kinetics, with the diffusion of the water molecules in the polymeric matrix faster than the chitosan chains relaxation [22,24].

\subsection{In Vitro NYS and PRO Release from Antifungal Films}

Nystatin and propolis release efficiencies (\%) were calculated based on their concentrations in PBS imersion solutions over time $(24 \mathrm{~h})$, as determined from their UV-VIS spectra (Figure S7, Supplementary Materials). The release of the drugs from the antifungal films during $5 \mathrm{~h}$ is graphically represented in Figure 5. As one may see from Figure 5a, all NYS charged films presented a quick release the first $10 \mathrm{~min}$ and progressively increasing release efficiency up to $48.6 \%$ (CS-NYS), 45.9\% (CS-NYS-PRO1), and 42.8\% (CS-NYS-PRO2) after $5 \mathrm{~h}$. Further, the NYS release continues to rise by $5-7 \%$ at $24 \mathrm{~h}$ (Table S2). The adding of propolis to CS-NYS formulation induced a lower NYS release efficiency, as the crosslinking between polyphenols and chitosan makes more difficult the diffusion of NYS through the resulted polymeric network (CS-NYS-PRO2 had higher propolis content and lowest release efficiency).

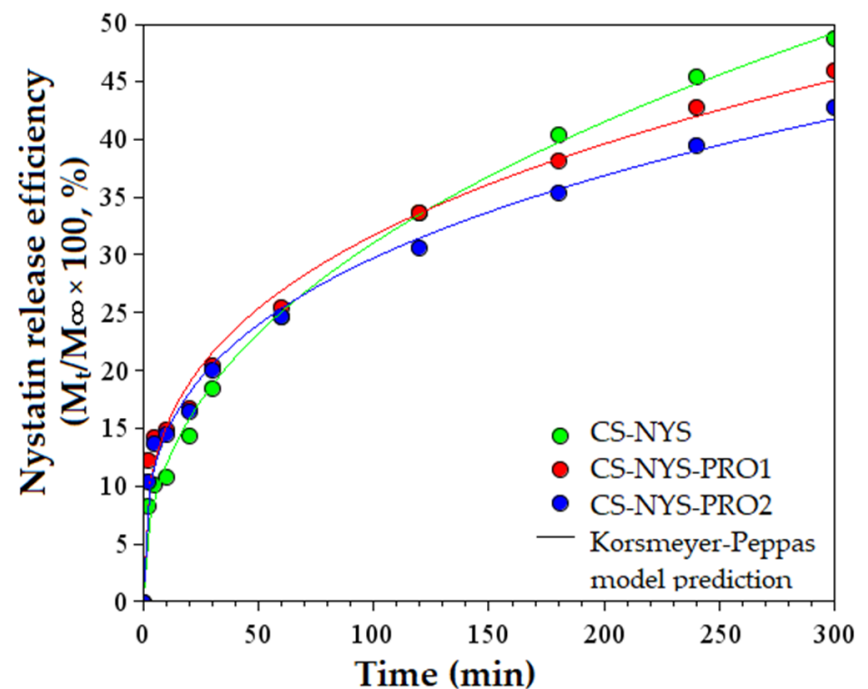

(a)

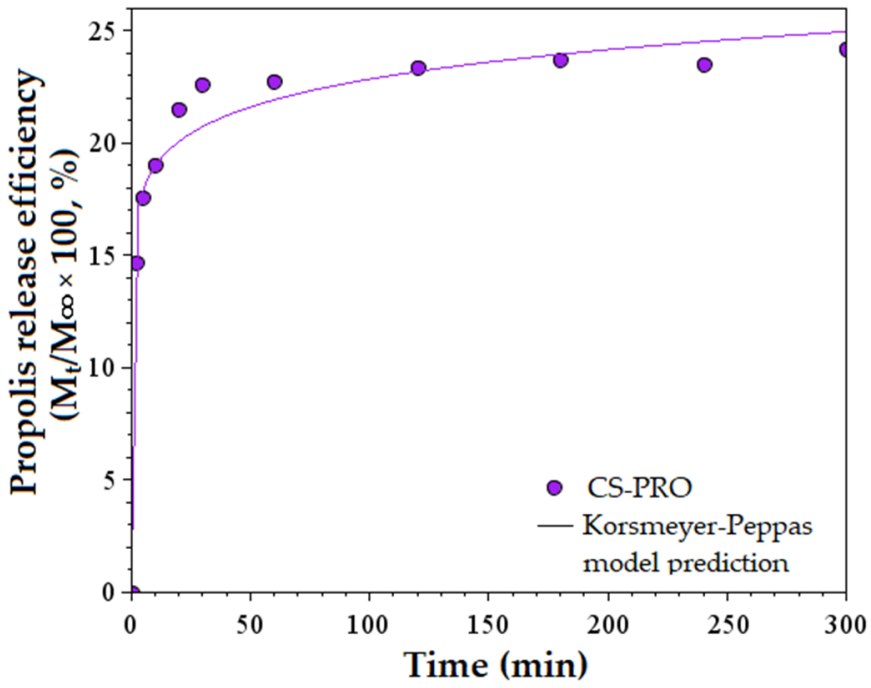

(b)

Figure 5. Release efficiency of: (a) Nystatin from CS-NYS, CS-PRO-NYS1 and CS-PRO-NYS2; (b) Propolis from CS-PRO; the experimental data were fitted based on Korsmeyer and Peppas kinetic model.

Due to the superposition of the absorptions of NYS on the characteristic UV-VIS band of PRO, the release efficiency of the later was represented for CS-PRO film only (Figure 5b). PRO release curve shows a burst effect the first $30 \mathrm{~min}$ (with a release efficiency of 22.58\%), followed by a plateau located at about $24.2 \%$, which lasts at the same value after $24 \mathrm{~h}$.

Korsmeyer and Peppas kinetic release model was applied for fitting the in vitro NYS and PRO release experimental data (Figure 5). For NYS, the model provided a good fitting, indicating that the release mechanism is based on diffusion through the polysaccharide matrix. The fitting of PRO release experimental data showed a good fitting the first $20 \mathrm{~min}$, followed by a satisfactory fitting up to $5 \mathrm{~h}$. By calculating kinetics parameters of the semiempirical matehmatical model (given in Table S2), it was established that the mechanims of both antifungal agents transport is based on Quasi-Fickian diffusion $(\mathrm{n}<0.5)$ and the release mechanism occurs from non-swellable matrix diffusion [26].

\subsection{Dynamic Vapor Sorption onto the Hydrogels}

The behavior of the hydrogel formulations in the presence of moisture was investigated and the water vapor sorption/desorption isotherms were represented in Figure S8 (Supplementary Materials). Based on the IUPAC classification the isotherms are related to 
Type V curves, specific to water sorption on hydrophobic micro- and mesoporous surfaces and indicate weak adsorbent-water interaction [27]. Similar isotherms were registered for other chitosan-based hydrogels [60,61].

The hydrogels containing both NYS and PRO presented enhanced water vapor barrier properties, with lower water sorption capacity values (89.8 for CS-NYS-PRO1 and 88.1\% CS-NYS-PRO2) as compared to the uncharged CS-LA sample (94.1\%) as given in Table S3. This may be explained by the simultaneous effects of hydrophobic NYS component and of chemical crosslinking of CS amino groups by polyphenols, which makes more difficult the diffusion of water vapors through the polymeric network. This behavior is supported by the results of swelling capacity of the films formulations (Figure 5).

The BET and BJH models were applied to evaluate the specific surface areas and the pore dimensions, respectively (Table S3, Supplementary Materials). The values obtained indicate the presence of larger mesopores for not charged CS-LA samples (width about $14 \mathrm{~nm}$ ) as compared to NYS and PRO loaded samples (pore widths between about 2 and $4 \mathrm{~nm}$ ). Moreover, the specific surface areas increased several times from $275 \mathrm{~m}^{2} / \mathrm{g}$ for CS-LA sample to 1035, 1379, 1444 and $1727 \mathrm{~m}^{2}$ /g for CS-PRO, CS-NYS, CS-NYS-PRO1, and CS-NYS-PRO2 samples, respectively, as an effect of both the nature and content of functional groups and the pore size over the complex mode of the sorption capacity of the studied samples.

\subsection{Rheological Properties of Chitosan Hydrogel Formulations}

The rheological properties of chitosan hydrogels (with and without active principles) were evaluated as functions of angular frequency or temperature (Figure 6). Preliminary deformation tests at $0.1-200 \%$ deformation range ( $\gamma$ of $10 \%$ ) confirmed that tests are in the linear viscoelastic regime (LVE). The dynamic oscillatory measurements were performed at $35^{\circ} \mathrm{C}$ (temperature close to that of physiological body temperature of $37^{\circ} \mathrm{C}$ ) and the properties such as elasic modulus $\left(G^{\prime}\right)$, viscous modulus $\left(G^{\prime \prime}\right)$ and complex viscosity $\left(\eta^{*}\right)$ were investigated in the range of $0.01-100 \mathrm{rad} / \mathrm{s}$.

To establish the type of the hydrogels, the evolution of $\mathrm{G}^{\prime}$ and $\mathrm{G}^{\prime \prime}$ at $35{ }^{\circ} \mathrm{C}$ and a $\gamma=10 \%$ vs. $\omega$ is represented in Figure $6 \mathrm{a}$ and their values at $\omega=1 \mathrm{~Hz}$ are given in Table S4, Supplementary Materials. All the hydrogels are characterized by increasing $\mathrm{G}^{\prime}$ and $G^{\prime \prime}$ moduli values with increasing angular frequency. As seen from this figure, the CS-LA, CS-NYS and CS-NYS-PRO1 hydrogels present a solid-like behavior ( $\mathrm{G}^{\prime}$ modulus higher than $G^{\prime \prime}$ modulus), which denotes a polymeric network structure that is self-dependent of the applied rheological stress parameters. On the contrary, the hydrogels with higher content of propolis (CS-PRO and CS-NYS-PRO2) exhibit a predominantly liquid-like behavior $\left(G^{\prime \prime}>G^{\prime}\right)$, indicating properties of a more viscous than elastic polymeric network. The rheological behavior of the hydrogels was also verified by the calculation of the loss tangent $(\tan \delta)$ as represented in Figure S9, Supplementary Materials. The subunitary values of the $\tan \delta$ confirms the gel like structure of the CS-LA, CS-NYS and CS-NYS-PRO1, while values higher than 1 of the loss tangents are found for the liquid-like behavior of the CS-PRO and CS-NYS-PRO2 hydrogels (Table S4, Supplementary Materials).

All chitosan-based hydrogels presented a linear decrease of the complex viscosity $\left(\eta^{*}\right)$ with the increase of the angular frequency (Figure 5b) induced by the breaking of the intermolecular forces and by the alignment of chitosan chains in the same direction with the applied stress. This behavior was observed by others in cationic hydrogel composites based on synthetic polymers and suggests a non-Newtonian behavior for all the range of angular frequencies, with a shear-thinning behavior [29].

The temperature sweep measurements were performed in the range of 5 to $40{ }^{\circ} \mathrm{C}$, as it was proved that the storage temperature of chitosan solution is favorable at $5^{\circ} \mathrm{C}$ as it reduces the polyssacharide decomposition [62] and the viscosity ( $\eta$ ) of the hydrogels was evaluated up to the human body temperature $\left(37^{\circ} \mathrm{C}\right)$. Figure $6 \mathrm{c}$ shows an expected trend of decreasing viscosity of chitosan hydrogels when temperature increases, due to the augmentation of the polymeric thermal motion. However, all the samples present increased 
viscosity for temperatures exceeding $35^{\circ} \mathrm{C}$ (more evident for CS-LA), mostly because of the moisture loss when subjected to higher temperatures [63].

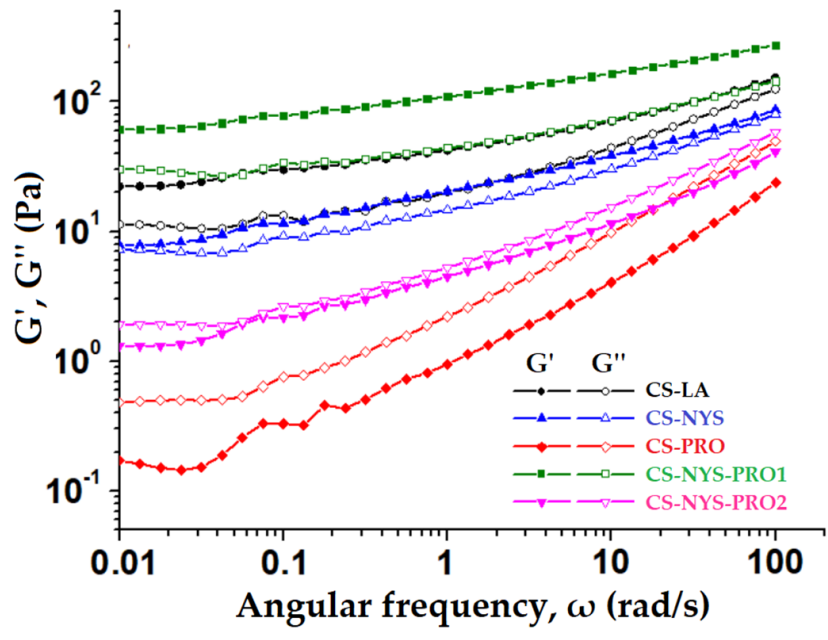

(a)

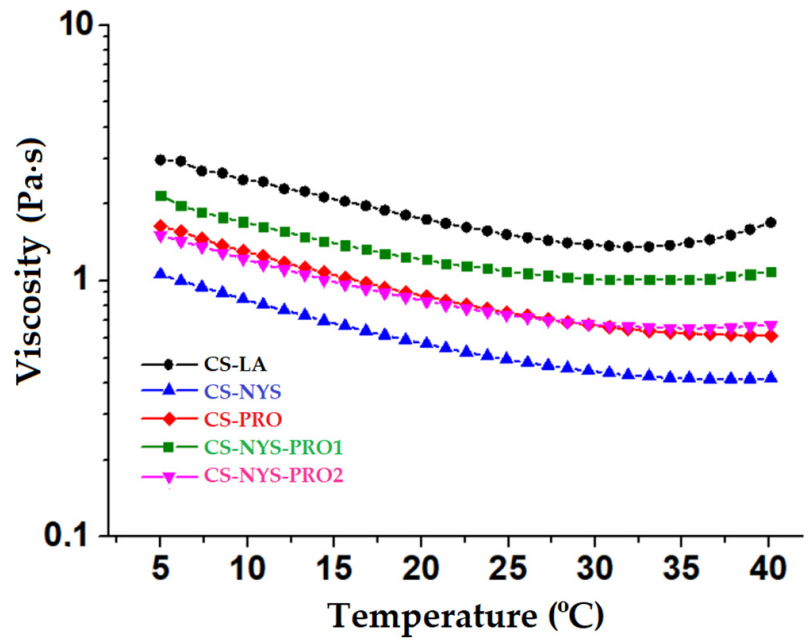

(c)

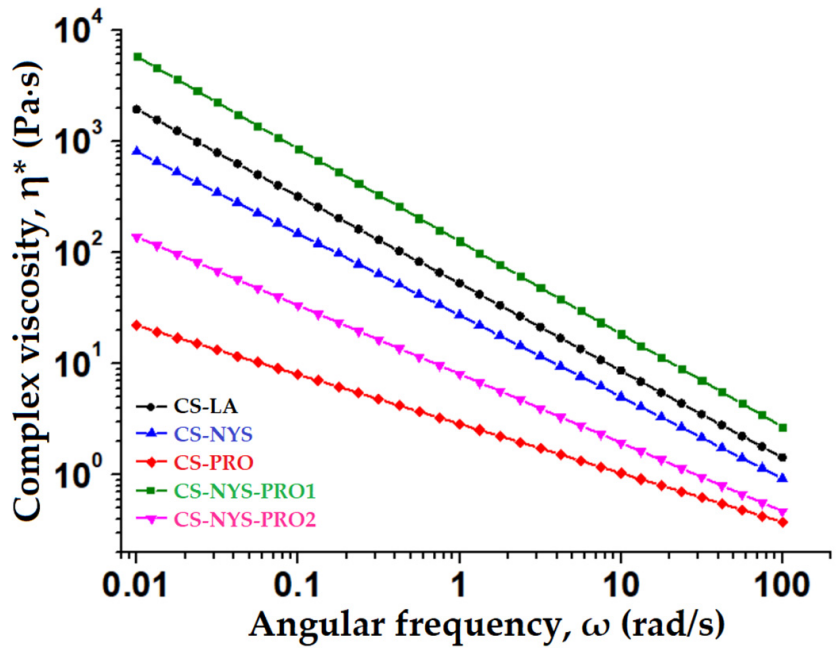

(b)

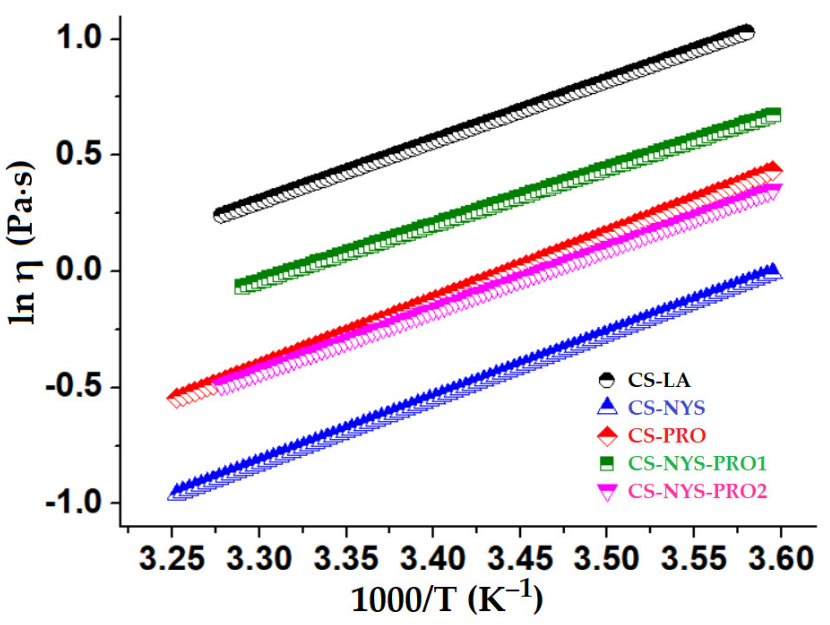

(d)

Figure 6. Rheological properties of chitosan hydrogel formulations: (a) dynamic viscoelastic moduli $\mathrm{G}^{\prime}$ (filled symbols) and $\mathrm{G}^{\prime \prime}$ (open symbols) dependence on angular frequency at constant temperature of $35{ }^{\circ} \mathrm{C}$ and $\gamma$ of $10 \%$; (b) complex viscosity $\left(\eta^{*}\right)$ as a function of angular frequency $\left(35^{\circ} \mathrm{C}\right.$ and $\gamma=10 \%$ ); (c) temperature influence on the viscosity of hydrogel formulations; (d) Arrhenius fitting of the experimental data.

The activation energy (Eף) for the viscous flow was calculated from the regression results obtained by Arrhenius fitting of the temperature-dependence curve of the viscosity (Figure 6d). Close to each other and positive activation energy (Eq) values (Table S4, Supplementary Materials) were registered for all hydrogels, as expected for solutions with thermo-thinning behavior (viscosity decrease with temperature increase).

\subsection{Antifungal Activity of Hydrogel Formulations}

The in vitro antifungal activity was investigated against two Candida species (Candida albicans and Candida glabrata) on hydrogels samples, using the agar disk diffusion method which supposes the addition of the hydrogels on the culture medium pre-inoculated with the microbial suspension, and measuring the clear zone caused by fungal growth inhibition around the hydrogels, after $48 \mathrm{~h}$ of incubation. The images of the inhibition zones and the average inhibition diameters are given in Figure S10, Supplementary Materials, and 
Figure 7, respectively. All the hydrogels killed the fungal cultures when placed in direct contact, but only chitosan hydrogels with NYS content (CS-NYS, CS-PRO-NYS1, CS-PRONYS2) presented inhibition of the fungal growth on a large area around the hydrogels, for both analyzed Candida strains. However, CS-NYS-PRO1 had the highest inhibition zone diameter (24 mm) compared with CS-NYS and CS-NYS-PRO2 (23, and $22 \mathrm{~mm}$ respectively) when evaluated against Candida albicans, which denotes the cumulative antifungal effect of NYS and PRO. The highest inhibition growth diameter against Candida glabrata was obtained for the CS-NYS hydrogel (19 mm), while CS-NYS-PRO1 and CS-NYS-PRO2 had diameters of 16 , and $12 \mathrm{~mm}$, respectively.

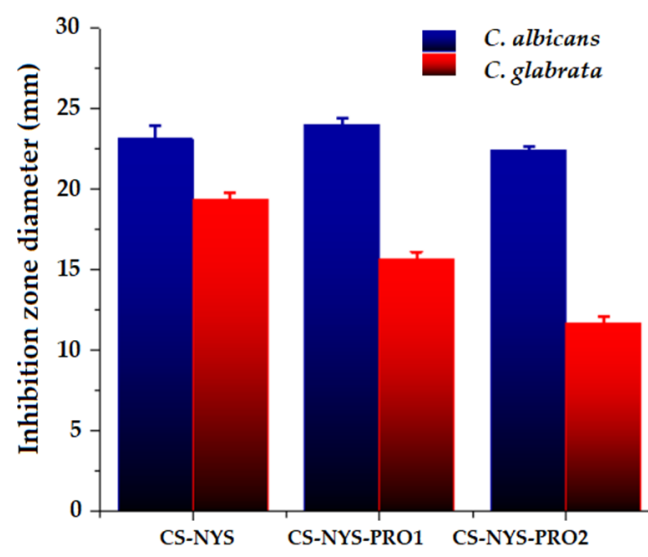

Figure 7. Diameters of the inhibition zones in the antifungal activity test of chitosan hydrogels against Candida albicans and Candida glabrata; error bars represent standard deviation (for $n=10$ ).

\subsection{Time-Kill Assay Test}

The time-kill kinetics against the Candida albicans (Figure 8) was assessed for the hydrogels that presented higher antifungal activity (CS-NYS and CS-NYS-PRO1), as compared with the hydrogel with less antifungal inhibition (CS-PRO) and a control sample. The time-kill assay supports the results previously obtained in agar plate antifungal testing against C. albicans, showing that CS-PRO-NYS1 exhibit the strongest and faster slowing down of the fungal growth (from the first $6 \mathrm{~h}$ ). A similar trend is identified also for the chitosan hydrogel charged with nystatin, which reveal fungal killing efficiency $<10^{1}$ CFUs $/ \mathrm{mL}$ in the first $12 \mathrm{~h}$ (Table S5). Corroborating data, it could be appreciated that the under-study chitosan hydrogels with nystatin and propolis have a potent fungicidal effect with a fungal burden reduction of 6-log killing (99.999\% killing and 10 fungi left) after $24 \mathrm{~h}$.

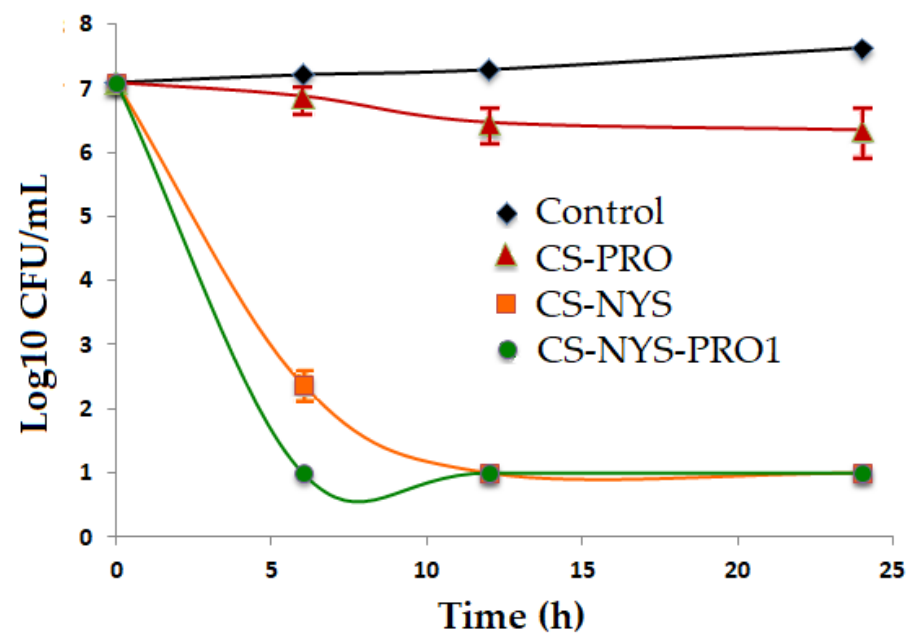

Figure 8. Time-kill curves for evaluation of the fungicidal activity of CS-NYS, CS-PRO and CS-NYSPRO1 against yeast cells of Candida albicans as compared to the control assay; the error bars represent standard deviation for time killing kinetics $(n=4)$. 


\section{Conclusions}

CS dissolved in aqueous lactic solution was demonstrated by structural (FTIR) and morphological (SEM, polarized light microscopy) investigations to successfully embed nystatin and/or propolis to yield gel-like or flexible film formulations. The antifungal films presented increased elasticity and mechanical properties close to those of soft tissues (Young's modulus lower than $1 \mathrm{MPa}$ ), adequate hydration capacities to maintain films bioadhesion and a progressive release of nystatin based on Quasi-Fickian diffusion mechanism, being suitable for application on buccal mucous membranes (cheek mucosa). As established by in vitro antifungal analysis, the samples containing higher amounts of propolis (CS-PRO and CS-NYS-PRO2) do not show noticeable activity, contrary to CS-NYS and CS-NYS-PRO1 (lower amount of PRO) samples, which proved to be efficient against C. albicans and C. glabrata. The results were confirmed by time-kill assay in synthetic vagina-simulative medium, where the hydrogel containing both NYS and smaller amounts of PRO (CS-PRO-NYS1) proved a combined effect on combating C. albicans, exhibiting the strongest and faster slowing down of fungal growth from the first $6 \mathrm{~h}$ of contact. Further studies are ongoing to demonstrate the additive or synergistic effect of these two active principles against candida species.

Supplementary Materials: The following supporting information can be downloaded at: https: / / www.mdpi.com/article/10.3390/polym14040689/s1, Figure S1: Nystatin powder: (a) Scanning electron microscopy images for nystatin; (b) particle size distribution histogram (particle sizes were determined using NIH Image J software); Figure S2: ${ }^{13} \mathrm{C}-\mathrm{RMN}$ spectrum of nystatin; IUPAC Name: (1S,3R,4R,7R,9R,11R,15S,16R,17R,18S,19E,21E,25E,27E,29E,31E,33R,35S,36R,37S)-33-[(2R,3S,4S,5S,6R)4-amino-3,5-dihydroxy-6-methyloxan-2-yl]oxy-1,3,4,7,9,11,17,37-octahydroxy-15,16,18-trimethyl-13oxo-14,39-dioxabicyclo[3 3.3.1] nonatriaconta-19,21,25,27,29,31-hexaene-36-carboxylic acid); signal attributions made according to ref. [44-46]; Figure S3: ${ }^{1} \mathrm{H}-\mathrm{RMN}$ spectrum of nystatin. IUPAC Name: 1S,3R,4R,7R,9R,11R,15S,16R,17R,18S,19E,21E,25E,27E, 29E,31E,33R,35S,36R,37S)-33- [(2R,3S, 4S,5S,6R)4-amino-3,5-dihydroxy-6-methyloxan-2-yl]oxy-1,3,4,7,9,11,17,37-octahydroxy-15,16,18-trimethyl-13oxo-14,39-dioxabicyclo[33.3.1]nonatriaconta-19,21,25,27,29,31-hexaene-36-carboxylic acid); signal attributions made according to ref. [44-46]; Figure S4: Chemical formula of chitosan with highlighting the functional groups: free primary amino groups $\left(\mathrm{NH}_{2}\right.$ to $\left.\mathrm{C} 2\right)$, primary hydroxyl group $(\mathrm{OH}$ to $\mathrm{C} 6$ ) and secondary hydroxyl groups (OH to $\mathrm{C} 3$ ); $m$ and $n$ represent the numbers of deacetylated (d-glucosamine) and N-acetyl-d-glucosamine repeating units, linked by (1-4)- $\beta$-glycosidic linkages, respectively; Figure S5: FTIR spectra of chitosan powder (CS) and chitosan gel (3\%) after dispersion in 2\% lactic acid solution (CS-LA); Figure S6: Characteristic stress-strain curves of the films: (a) without biological active compounds (CS-LA); (b) nystatin, propolis, and nystatin/propolis loaded chitosan films (CS-NYS, CS-PRO, CS-NYS-PRO1, CS-NYS-PRO2); Table S1: Parameters of pseudo-second order (PSO) and Korsmeyer-Peppas (K-P) kinetic models, where $\mathrm{k}_{\mathrm{s}}$ is the constant of the swelling rate, $\mathrm{S}_{\mathrm{e}}$ is the theoretical swelling capacity at equilibrium, $\mathrm{k}_{\mathrm{p}}$ is a constant dependent on the polymeric network; $\mathrm{n}$ is the diffusion parameter of aqueous PBS in the formulation film and SD represents the standard deviation of $\mathrm{n}=11$ ); swelling capacity in PBS of chitosan charged films after 5 and 24 h; Figure S7: Evolution in time of UV-VIS spectra of: nystatin released from CS-NYS (a), CS-NYS-PRO1 (b) and CS-NYS-PRO2 (c); propolis released from CS-PRO (d); Table S2: NYS and PRO release from chitosan films: Korsmeyer-Peppas kinetics parameters ( $\mathrm{k}$ represents the transport constant, $\mathrm{n}$ is the diffusion exponent and SD is standard deviation of $\mathrm{n}=11$ ), and release efficiency after 5 and $24 \mathrm{~h}$.; Figure S8. Sorption/desorption isotherms for the hydrogel formulations; Table S3. Surface parameters of the hydrogels evaluated based on adsorption/desorption isotherms: water vapor sorption capacity, final weight $(\mathrm{W})$; average pore size $\left(\mathrm{r}_{\mathrm{pm}}\right)$ and BET data (surface area and monolayer weight); Figure S9: The loss tangent $\left(\tan \delta=G^{\prime \prime} / G^{\prime}\right)$ as a function of angular frequency; Table S4: Viscoelastic parameters $\left(\mathrm{G}^{\prime}, \mathrm{G}^{\prime \prime}\right.$ and $\left.\tan \delta\right)$ at a frequency of $1 \mathrm{~Hz}$ and viscous flow activation energy (En) calculated by fitting the temperature-dependence curve of the viscosity by Arrhenius equation; Figure S10. Antifungal activity of chitosan hydrogels against: (a) C. albicans and (b) C. glabrata; Table S5: Killing-time efficiency of CS-NYS, CS-PRO and CS-NYS-PRO1 hydrogels, against Candida albicans in $24 \mathrm{~h}$ as compared to the control test. 
Author Contributions: Conceptualization, A.-C.H. and V.H.; methodology, A.-C.H., C.C., P.S. and M.M.; formal analysis, C.C.; investigation, A.-C.H., A.-C.B. and R.D.; resources, P.S, V.H. and M.M.; writing-original draft preparation, A.-C.H.; writing—review and editing, M.M. and V.H.; supervision, V.H. and B.C.S. All authors have read and agreed to the published version of the manuscript.

Funding: This research received no external funding.

Institutional Review Board Statement: Not applicable.

Informed Consent Statement: Not applicable.

Data Availability Statement: Not applicable.

Acknowledgments: One of the authors (A.-C.H.) acknowledges the partial support of the PhDSchool of Advanced Studies of the Romanian Academy (SCOSAAR) for her PhD thesis entitled Chitosan based materials for biomedical, energy and environmental applications; PhD degree confirmation by order of the Romanian Minister of Education No 4640/18.08.2021.

Conflicts of Interest: The authors declare no conflict of interest.

\section{References}

1. Spampinato, C.; Leonardi, D. Candida infections, causes, targets, and resistance mechanisms: Traditional and alternative antifungal agents. Biomed Res. Int. 2013, 2013, 204237. [CrossRef] [PubMed]

2. Bongomin, F.; Gago, S.; Oladele, R.; Denning, D. Global and multi-national prevalence of fungal diseases-Estimate precision. J. Fungi 2017, 3, 57. [CrossRef] [PubMed]

3. Vallabhaneni, S.; Mody, R.K.; Walker, T.; Chiller, T. The global burden of fungal diseases. Infect. Dis. Clin. North Am. 2016, 30, 1-11. [CrossRef] [PubMed]

4. Mareković, I.; Pleško, S.; Rezo Vranješ, V.; Herljević, Z.; Kuliš, T.; Jandrlić, M. Epidemiology of candidemia: Three-year results from a croatian tertiary care hospital. Fungi 2021, 7, 267. [CrossRef] [PubMed]

5. Wiederhold, N. Antifungal resistance: Current trends and future strategies to combat. Infect. Drug Resist. 2017, 10, 249-259. [CrossRef]

6. Peptu, C.; Humelnicu, A.-C.; Rotaru, R.; Fortuna, M.E.; Patras, X.; Teodorescu, M.; Tamba, B.I.; Harabagiu, V. chitosan-based drug delivery systems. In Chitin and Chitosan: Properties and Applications, 1st ed.; Van den Broek, L.A.M., Boeriu, C.G., Eds.; John Wiley \& Sons Ltd.: West Sussex, UK, 2020; pp. 259-289.

7. Shelke, N.B.; James, R.; Laurencin, C.T.; Kumbar, S.G. Polysaccharide bio-materials for drug delivery and regenerative engineering. Polym. Adv. Technol. 2014, 25, 448-460. [CrossRef]

8. Aranaz, I.; Alcántara, A.R.; Civera, M.C.; Arias, C.; Elorza, B.; Heras Caballero, A.; Acosta, N. Chitosan: An overview of its properties and applications. Polymers 2021, 13, 3256. [CrossRef]

9. Yu, J.; Wang, D.; Geetha, N.; Khawar, K.M.; Jogaiah, S.; Mujtaba, M. Current trends and challenges in the synthesis and applications of chitosan-based nanocomposites for plants: A review. Carbohydr. Polym. 2021, 261, 117904. [CrossRef]

10. Sood, A.; Gupta, A.; Agrawal, G. Recent advances in polysaccharides based bio-materials for drug delivery and tissue engineering applications. Carbohydr. Polym. Technol. Appl. 2021, 2, 100067. [CrossRef]

11. Martín-Villena, M.J.; Fernández-Campos, F.; Calpena-Campmany, A.C.; Bozal-de Febrer, N.; Ruiz-Martínez, M.A.; Clares-Naveros, B. Novel microparticulate systems for the vaginal delivery of nystatin: Development and characterization. Carbohydr. Polym. 2013, 94, 1-11. [CrossRef]

12. Martín, M.J.; Calpena, A.C.; Fernández, F.; Mallandrich, M.; Gálvez, P.; Clares, B. Development of alginate microspheres as nystatin carriers for oral mucosa drug delivery. Carbohydr. Polym. 2015, 117, 140-149. [CrossRef] [PubMed]

13. Fuentefria, A.M.; Pippi, B.; Dalla Lana, D.F.; Donato, K.K.; de Andrade, S.F. Antifungals discovery: An insight into new strategies to combat antifungal resistance. Lett. Appl. Microbiol. 2017, 66, 2-13. [CrossRef] [PubMed]

14. Revie, N.M.; Iyer, K.R.; Robbins, N.; Cowen, L.E. Antifungal drug resistance: Evolution, mechanisms and impact. Curr. Opin. Microbiol. 2018, 45, 70-76. [CrossRef]

15. Bell, A.S. Major Antifungal Drugs. In Comprehensive Medicinal Chemistry II, 8th ed.; Taylor, J.B., Triggle, D.J., Eds.; Elsevier: Oxford, UK, 2006; Volume 7, pp. 445-468.

16. Shaikh, M.S.; Alnazzawi, A.; Habib, S.R.; Lone, M.A.; Zafar, M.S. Therapeutic role of nystatin added to tissue conditioners for treating denture-induced stomatitis: A systematic review. Prosthesis 2021, 3, 61-74. [CrossRef]

17. Zager, R.A. Polyene antibiotics: Relative degrees of in vitro cytotoxicity and potential effects on tubule phospholipid and ceramide content. Am. J. Kidney Dis. 2000, 36, 238-249. [CrossRef] [PubMed]

18. Rathore, S.S.; Ramakishnan, J.; Raman, T. Recent advancement in combinational antifungal therapy and immunotherapy. In Recent Trends in Antifungal Agents, 1st ed.; Basak, A., Chakraborty, R., Mandal, S., Eds.; Springer: New Delhi, India, 2016; pp. 75-95.

19. Humelnicu, A.-C.; Samoila, P.; Asandulesa, M.; Cojocaru, C.; Bele, A.; Marinoiu, A.T.; Saccà, A.; Harabagiu, V. Chitosan-sulfated titania composite membranes with potential applications in fuel cell: Influence of cross-linker nature. Polymers 2020, $12,1125$. [CrossRef] 
20. Singleton, V.L.; Orthofer, R.; Lamuela-Raventós, R.M. Analysis of total phenols and other oxidation substrates and antioxidants by means of Folin-Ciocalteu reagent. Meth. Enzymol. 1999, 299, 152-178. [CrossRef]

21. Li, X.; Wang, Y.; Li, A.; Ye, Y.; Peng, S.; Deng, M.; Jiang, B. A novel ph- and salt-responsive n-succinyl-chitosan hydrogel via a one-step hydrothermal process. Molecules 2019, 24, 4211. [CrossRef]

22. Budianto, E.; Amalia, A. Swelling behavior and mechanical properties of chitosan-poly(n-vinyl-pyrrolidone) hydrogels. J. Polym. Eng. 2020, 40, 551-560. [CrossRef]

23. Kipcak, A.S.; Ismail, O.; Doymaz, I.; Piskin, S. Modeling and investigation of the swelling kinetics of acrylamide-sodium acrylate hydrogel. J. Chem. 2014, 2014, 1-8. [CrossRef]

24. Peppas, N. Hydrogels in pharmaceutical formulations. Eur. J. Pharm. Biopharm. 2000, 50, 27-46. [CrossRef]

25. Korsmeyer, R.W.; Peppas, N.A. Effect of the morphology of hydrophilic polymeric matrices on the diffusion and release of water soluble drugs. J. Membr. Sci. 1981, 9, 211-227. [CrossRef]

26. Rehman, Q.; Hamid Akash, M.S.; Rasool, M.F.; Rehman, K. Role of kinetic models in drug stability. In Drug Stability and Chemical Kinetics; Akash, M.S.H., Rehman, K., Eds.; Springer: Singapore, 2020; pp. 155-166. [CrossRef]

27. Thommes, M.; Kaneko, K.; Neimark, A.V.; Olivier, J.P.; Rodriguez-Reinoso, F.; Rouquerol, J.; Sing, K.S.W. Physisorption of gases, with special reference to the evaluation of surface area and pore size distribution (IUPAC Technical Report). Pure Appl. Chem. 2015, 87, 1051-1069. [CrossRef]

28. Hernández-Castillo, D.J.; de la Cruz Hernández, E.N.; Frías Márquez, D.M.; Tilley, R.D.; Gloag, L.; Owen, P.Q.; López González, R.; Alvarez Lemus, M.A. Albendazole release from silica-chitosan nanospheres. In vitro study on cervix cancer cell lines. Polymers 2021, 13, 1945. [CrossRef]

29. Sun, M.; Sun, H.; Wang, Y.; Sánchez-Soto, M.; Schiraldi, D. The Relation between the rheological properties of gels and the mechanical properties of their corresponding aerogels. Gels 2018, 4, 33. [CrossRef]

30. Malkin, A.Y.; Isayev, A. Viscoelasticicty. In Rheology: Concepts, Methods, and Applications, 3rd ed.; Malkin, A.Y., Isayev, A., Eds.; ChemTec Publishing: Toronto, ON, Canada, 2017; pp. 45-49.

31. Rehman, T.U.; Shah, L.A. Rheological investigation of go doped p(aptmacl) composite hydrogel. Z. Phys. Chem. 2021, 235, 329-343 [CrossRef]

32. Canton, E.; Peman, J.; Gobernado, M.; Viudes, A.; Espinel-Ingroff, A. Patterns of amphotericin b killing kinetics against seven candida species. Antimicrob. Agents Chemother. 2004, 48, 2477-2482. [CrossRef]

33. Moosa, M.-Y.S.; Sobel, J.D.; Elhalis, H.; Du, W.; Akins, R.A. Fungicidal Activity of fluconazole against candida albicans in a synthetic vagina-simulative medium. Antimicrob. Agents Chemother. 2003, 48, 161-167. [CrossRef]

34. Marques, M.R.; Loebenberg, R.; Almukainzi, M. Simulated biological fluids with possible application in dissolution testing. Dissolution Technol. 2011, 18, 15-28. [CrossRef]

35. Perchyonok, V.T.; Zhang, S.; Oberholzer, T. Alternative chitosan based drug delivery system to fight oral mucositis: Synergy of conventional and bioactives towards the optimal solution. Curr. Nanosci. 2012, 8, 541-547. [CrossRef]

36. Perchyonok, V.T.; Zhang, S.; Grobler, S.; Oberholzer, T. Insights into and relative effect of chitosan-H, chitosan-H-propolis, chitosan-H-propolis-nystatin and chitosan-H-nystatin on dentine bond strength. Eur. J. Dent. 2013, 7, 412-418. [CrossRef] [PubMed]

37. Perchyonok, V.T.; Zhang, S.; Basson, N.; Grobler, S.; Oberholzer, T.; Massey, W. Insights into chitosan based gels as functional restorative biomaterials prototypes: In vitro approach. Open J. Stomat. 2013, 3, 22-30. [CrossRef]

38. Perchyonok, V.-T.; Zhang, S.; Oberholzer, T. Novel melatonin-chitosan hydrogels as suitable oral bio-drug delivery systems to fight oral mucositis: Synergy of antioxidants and bioactives in action. Curr. Org. Chem. 2012, 16, 2430-2436. [CrossRef]

39. Friedman, D.I. Stable Oil-in-Glycerin Emulsion. European Patent EP1077713A1, 28 February 2001.

40. Dallan, P.R.M.; da Luz Moreira, P.; Petinari, L.; Malmonge, S.M.; Beppu, M.M.; Genari, S.C.; Moraes, A.M. Effects of chitosan solution concentration and incorporation of chitin and glycerol on dense chitosan membrane properties. J. Biomed. Mater. Res. B Appl. Biomater. 2007, 80B, 394-405. [CrossRef] [PubMed]

41. Ma, Y.; Xin, L.; Tan, H.; Fan, M.; Li, J.; Jia, Y.; Ling, Z.; Chen, Y.; Hu, X. Chitosan membrane dressings toughened by glycerol to load antibacterial drugs for wound healing. Mater. Sci. Eng. C 2017, 81, 522-531. [CrossRef]

42. Peh, K.; Khan, T.; Ch'ng, H. Mechanical, bioadhesive strength and biological evaluations of chitosan films for wound dressing. $J$. Pharm. Pharm. Sci. 2000, 3, 303-311.

43. Niamsa, N.; Baimark, Y. Preparation and characterization of highly flexible chitosan films for use as food packaging. Am. J. Food Technol. 2009, 4, 162-169. [CrossRef]

44. Szwarc, K.; Płosiński, M.; Czerniejewska, K.; Laskowski, T.; Leniak, A.; Czub, J.; Kubica, P.; Sowiński, P.; Pawlaka, J.; Borowski, E. Intramolecular transformation of an antifungal antibiotic nystatin A1 into its isomer, iso -nystatin A1 structural and molecular modeling studies. Magn. Reson. Chem. 2016, 54, 953-961. [CrossRef]

45. Volpon, L.; Lancelin, J.-M. Solution NMR structure of five representative glycosylated polyene macrolide antibiotics with a sterol-dependent antifungal activity. Eur. J. Biochem. 2002, 269, 4533-4541. [CrossRef]

46. Sletta, H.; Borgos, S.E.F.; Bruheim, P.; Sekurova, O.N.; Grasdalen, H.; Aune, R.; Ellingsen, T.E.; Zotchev, S.B. Nystatin biosynthesis and transport: nysH and nysG genes encoding a Putative ABC transporter system in Streptomyces noursei ATCC 11455 are required for efficient conversion of 10-deoxynystatin to nystatin. Antimicrob. Agents Chemother. 2005, 49, 4576-4583. [CrossRef] 
47. Benavent, C.; Torrado-Salmerón, C.; Torrado-Santiago, S. Development of a solid dispersion of nystatin with maltodextrin as a carrier agent: Improvements in antifungal efficacy against Candida spp. biofilm infections. Pharmaceuticals 2021, 14, 397. [CrossRef] [PubMed]

48. Mandru, M.; Ciobanu, C.; Ignat, M.E.; Popa, M.; Verestiuc, L.; Vlad, S. Sustained release of nystatin from polyurethane membranes for biomedical applications. Dig. J. Nanomater. Biostruct. 2011, 6, 1227-1238.

49. Rajczak, E.; Tylkowski, B.; Constantí, M.; Haponska, M.; Trusheva, B.; Malucelli, G.; Giamberini, M. Preparation and characterization of uv-curable acrylic membranes embedding natural antioxidants. Polymers 2020, 12, 358. [CrossRef] [PubMed]

50. Svečnjak, L.; Marijanović, Z.; Okińczyc, P.; Marek Kuś, P.; Jerković, I. Mediterranean propolis from the adriatic sea islands as a source of natural antioxidants: Comprehensive chemical biodiversity determined by GC-MS, FTIR-ATR, UHPLC-DAD-QqTOFMS, DPPH and FRAP assay. Antioxidants 2020, 9, 337. [CrossRef]

51. Villalobos, K.; Rojas, H.; González-Paz, R.; Granados, D.B.; González-Masís, J.; Baudrit, J.V.; Corrales-Ureña, Y.R. Production of starch films using propolis nanoparticles as novel bioplasticizer. J. Renew. Mater. 2017, 5, 189-198. [CrossRef]

52. Velásquez-Cock, J.; Ramírez, E.; Betancourt, S.; Putaux, J.-L.; Osorio, M.; Castro, C.; Ganán, P.; Zuluaga, R. Influence of the acid type in the production of chitosan films reinforced with bacterial nanocellulose. Int. J. Biol. Macromol. 2014, 69, 208-213. [CrossRef]

53. Liu, Y.; Wang, S.; Zhang, R. Composite poly(lactic acid)/chitosan nanofibrous scaffolds for cardiac tissue engineering. Int. J. Biol. Macromol. 2017, 103, 1130-1137. [CrossRef]

54. He, Y.; Miao, J.; Chen, S.; Zhang, R.; Zhang, L.; Tang, H.; Yang, H. Preparation and characterization of a novel positively charged composite hollow fiber nanofiltration membrane based on chitosan lactate. RSC Adv. 2019, 9, 4361-4369. [CrossRef]

55. Bhattarai, N.; Ramay, H.R.; Chou, S.H.; Zhang, M. Chitosan and lactic acid-grafted chitosan nanoparticles as carriers for prolonged drug delivery. Int. J. Nanomed. 2006, 1, 181-187. [CrossRef]

56. Ambrosio-Martín, J.; Fabra, M.J.; Lopez-Rubio, A.; Lagaron, J.M. An effect of lactic acid oligomers on the barrier properties of polylactide. J. Mater. Sci. 2014, 49, 2975-2986. [CrossRef]

57. Campos, M.G.N.; Mei, L.H.I.; Santos, A.R., Jr. Sorbitol-plasticized and neutralized chitosan membranes as skin substitutes. Mater. Res. 2015, 18, 781-790. [CrossRef]

58. Gleadall, A.; Ruiz-Cantu, L. Transplantable scaffolds. In 3D Printing in Medicine and Surgery-Applications in Healthcare, 1st ed.; Thomas, D.J., Singh, D., Eds.; Woodhead Publishing: Kidlington, UK, 2021; pp. 199-222.

59. Koland, M.; Vijayanarayana, K.; Charyulu, R.; Prabhu, P. In vitro and in vivo evaluation of chitosan buccal films of ondansetron hydrochloride. Int. J. Pharm. Investig. 2011, 1, 164-171. [CrossRef] [PubMed]

60. Ipate, A.-M.; Serbezeanu, D.; Bargan, A.; Hamciuc, C.; Ochiuz, L.; Gherman, S. Poly(vinylpyrrolidone)-chitosan hydrogels as matrices for controlled drug release. Cellul. Chem. Technol. 2021, 55, 63-73. [CrossRef]

61. Butnaru, E.; Stoleru, E.; Brebu, M.; Darie-Nita, R.; Bargan, A.; Vasile, C. Chitosan-based bionanocomposite films prepared by emulsion technique for food preservation. Materials 2019, 12, 373. [CrossRef]

62. Nguyen, T.T.B.; Hein, S.; Ng, C.-H.; Stevens, W.F. Molecular stability of chitosan in acid solutions stored at various conditions. J. Appl. Polym. Sci. 2007, 107, 2588-2593. [CrossRef]

63. Viljoen, J.M.; Steenekamp, J.H.; Marais, A.F.; Kotzé, A.F. Effect of moisture content, temperature and exposure time on the physical stability of chitosan powder and tablets. Drug. Dev. Ind. Pharm. 2013, 40, 730-742. [CrossRef] 